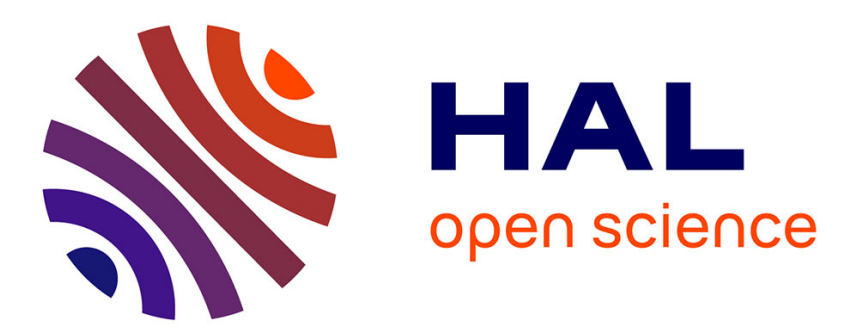

\title{
Nanomorphology of eco-friendly colloidal inks, relating non-fullerene acceptor surface energy to structure formation
}

Matthew G Barr, Sylvain Chambon, Adam Fahy, Timothy W Jones, Matthew A Marcus, A. Kilcoyne, Paul C Dastoor, Matthew J Griffith, Natalie P Holmes

\section{To cite this version:}

Matthew G Barr, Sylvain Chambon, Adam Fahy, Timothy W Jones, Matthew A Marcus, et al.. Nanomorphology of eco-friendly colloidal inks, relating non-fullerene acceptor surface energy to structure formation. Materials Chemistry Frontiers, 2021, 5 (5), pp.2218-2233. 10.1039/D0QM00980F . hal-03420257

\section{HAL Id: hal-03420257 https://hal.science/hal-03420257}

Submitted on 9 Nov 2021

HAL is a multi-disciplinary open access archive for the deposit and dissemination of scientific research documents, whether they are published or not. The documents may come from teaching and research institutions in France or abroad, or from public or private research centers.
L'archive ouverte pluridisciplinaire HAL, est destinée au dépôt et à la diffusion de documents scientifiques de niveau recherche, publiés ou non, émanant des établissements d'enseignement et de recherche français ou étrangers, des laboratoires publics ou privés. 


\section{Nanomorphology of Eco-Friendly Colloidal Inks, Relating Non- Fullerene Acceptor Surface Energy to Structure Formation}

Received 00th January 20xx, Accepted 00th January $20 x x$ DOI: $10.1039 / x 0 x \times 00000 x$

Matthew G. Barr, ${ }^{a}$ Sylvain Chambon, ${ }^{* b, c}$ Adam Fahy, ${ }^{a}$ Timothy W. Jones, d Matthew A. Marcus, ${ }^{\text {e } A . ~}$ L. David Kilcoyne, ${ }^{\text {e }}$ Paul C. Dastoor, ${ }^{a}$ Matthew J. Griffith, ${ }^{\text {a,f }}$ and Natalie P. Holmes *a,g

Nanoengineered, eco-friendly, solution-processable electroactive materials are in demand for the growing field of printed electronics, and these material requirements can be achieved by the development of waterborne colloidal dispersions. Functionality in these composite materials can be tuned by thermodynamically modifying the material nanomorphology, often by creation of kinetically stabilized aqueous nanoparticle dispersions. In this work we demonstrate that the internal structure of organic nanoparticles is controlled by the surface energy difference between the polymeric donor material and the non-fullerene acceptor (NFA) material. Nanoparticles of the following donor-acceptor combinations, suitable for printed organic photovoltaics, have been synthesized: TQ1:N2200, TQ1:PNDIT10, P3HT:N2200, P3HT:o-IDTBR and P3HT:eh-IDTBR. Advanced synchrotron-based X-ray spectroscopy and microscopy are used to correlate the formation of core-shell nanoparticle morphology to the material surface energy. We subsequently present a viable avenue for customizing the blended nanoparticle structure into (i) core-shell, (ii) molecularly intermixed, or (iii) inverted shell-core structures. Our results showed that TQ1:PNDIT10 and P3HT:O-IDTBR nanoparticles were comprised of a donor-rich shell and an NFA-rich core, however, interestingly we show a reversal to the inverse NFA shell / donor core structure for TQ1:N2200, P3HT:N2200 and P3HT:eh-IDTBR nanoparticles, driven by the low surface energy of $\mathrm{N} 2200\left(23.7 \mathrm{~mJ} \mathrm{~m}^{-2}\right)$ and eh-IDTBR (18.3 $\left.\mathrm{mJ} \mathrm{m} \mathrm{m}^{-2}\right)$. This article is the first report of a flipped nanoparticle core-shell morphology comprising an NFA-rich shell for the miniemulsion synthesis route. The composition of the shells and cores was able to be controlled by the differential mismatch in the surface energy of the donor and acceptor materials, with $\Delta G_{\text {surface }}>0, \Delta G_{\text {surface }}=0$, and $\Delta G_{\text {surface }}<0$ for acceptor core - donor shell, molecularly intermixed, and acceptor shell - donor core, respectively. Accordingly, we introduce an entirely overlooked new figure of merit (FoM) for customizing nanoparticulate colloidal inks: tunable surface energy of non-fullerene-based semiconductors. The establishment of this FoM opens up electroactive material design to a wide range of functional printing applications with varying device and ink structure requirements, thereby reshaping the nanoengineering toolkit for waterborne colloidal dispersions and hence printed electronics.

\section{Introduction}

Nanoparticles formed from electroactive materials have been heavily studied as the fundamental building blocks within numerous multidisciplinary fields. Such interest arises from a well-established ability to obtain differences in chemical, electrical, optical, and structural properties in nanostructured

\footnotetext{
a. Centre for Organic Electronics, University of Newcastle, Callaghan, NSW 2308 Australia

b. University of Bordeaux, IMS, CNRS, UMR 5218, Bordeaux INP, ENSCBP, F-33405 Talence, France

LIMMS/CNRS-IIS (UMI2820), Institute of Industrial Science, The University of Tokyo, 4-6-1 Komaba, Meguro-ku, Tokyo, 153-8505, Japan

CSIRO Energy Centre, Mayfield West, NSW 2304, Australia

e. Advanced Light Source, Lawrence Berkeley National Laboratory, Berkeley, CA 94720, USA

f. School of Aerospace, Mechanical and Mechatronic Engineering, University of Sydney, Camperdown, NSW 2006, Australia

g. Australian Centre for Microscopy and Microanalysis, University of Sydney, Madsen Building F09, NSW 2006, Australia

*Corresponding Author: Natalie P. Holmes, natalie.holmes@sydney.edu.au, Sylvain Chambon, chambon@iis.u-tokyo.ac.jp Electronic Supplementary Information (ESI) available: [details of any supplementary information available should be included here]. See DOI: 10.1039/x0xx00000x
}

materials compared to their bulk analogues. The ability to tune these nanomaterial properties through relatively simple synthetic chemical modifications that control nanoparticle size, shape, and function has allowed ground-breaking advances in catalysis, ${ }^{1-5}$ quantum dots, $^{6-8}$ biosensors and medical diagnostics, ${ }^{9-12}$ transistors, ${ }^{13}$ photovoltaics, ${ }^{14,15}$ and printed electronics. ${ }^{16-18}$ Successful incorporation of desirable nanoscale structure requires control of the interactions of individual materials with their surroundings, including other reagents such as secondary electroactive materials, solvent molecules, additives and stabilizing surfactant interfaces. ${ }^{19,20}$

In recent years, technology based on solution-processable electroactive organic molecules for organic photovoltaics (OPV) has made a leap forward due to the rapid development of nonfullerene acceptors (NFAs). This new class of organic semiconductors offers several advantages compared to the commonly used fullerene derivatives as the NFA chemical structure can be tuned through synthetic chemistry routes to modify optoelectronic properties. Advantages delivered through this synthetic flexibility include broad and strong optical absorption, bandgap $\left(E_{g}\right)$ tunability, reduced synthetic 
costs and superior morphological stability in device applications. ${ }^{21,22}$ These new materials are already producing exceptional results in printed electronics, including OPV, demonstrating record power conversion efficiencies (PCE) that exceed $18 \% .^{23,24}$ However, although organic printable technology has many reported advantages, ${ }^{25}$ the technology is not yet eco-friendly. One of the remaining challenges is the replacement of the halogenated and/or aromatic solvents (such as chloroform, dichloromethane and chlorobenzene) with environmentally friendly inks. The most attractive alternative in this regard is to move to water-based inks. The first efforts to shift from organic solvents to water appeared in 2002 with the work of Landfester et al. ${ }^{26-28}$ The authors applied a miniemulsion method to create blended donor and acceptor nanoparticles. Despite a poor device performance in comparison to blended bulk solutions - the concept of waterborne nanoparticulate organic electroactive inks was born. For several years, fullerene acceptor materials (in combination with polymer donor materials) were employed exclusively, with various thermodynamic treatments investigated to try and tune the nanoparticle structure. However, the electronic devices fabricated from these nanoparticle inks always exhibited poorer performance than their bulk solution counterparts. ${ }^{29}$ More recently, P3HT was replaced by a low band-gap polymer, PBDTTPD, ${ }^{30}$ which in combination with fullerene derivatives was able to increase device performances observed in photovoltaic devices (PCEs up to $3.8 \%$ ), however, performance still remained about half of that observed for the bulk solution mixtures. In 2018, Xie et al. ${ }^{15}$ combined the nanoprecipitation method, an alternative method to generate nanoparticles dispersed in water, ${ }^{31}$ and the use of a surfactant (poloxamer Pluronic F127) to synthesize a different kind of donor:NFA nanoparticle. Using a surfactantstripping technique, they managed to remove the excess of surfactant and obtained a step-change advance in device performance (PCE of $7.5 \%$ with PBQ-QF:ITIC). Critically, key performance metrics in devices created from a blended nanoparticle ink now approached that obtained for the intermixed bulk solution. ${ }^{15}$ This last report indicates that developing waterborne nanoparticulate electroactive inks with NFAs is a promising route towards high performance ecofriendly printed electronic devices. Nonetheless, there remains a lack of understanding regarding the specifics of deliberately engineering performance in these nanoparticle ink systems. Indeed, over the past decade, the switch to new donor and acceptor materials has improved device performance in conjunction with improved optoelectronic properties of the materials (such as enhanced light absorption or band energy modulations). However, it was not until the most recent reports of NFA investigations where the nanoparticle device performance suddenly began to rival that of the bulk solution counterparts. ${ }^{15}$ This development suggests that there is an additional benefit to the NFA materials that has not been available in the past; the ability to tune the nanoscale morphology in addition to the optoelectronic properties of the nanoparticles.
Fullerene derivatives have been for many years the standard organic semiconductor used as solution-processable electron acceptors in printed electronics applications. ${ }^{32,33}$ When employed in combination with a polymeric donor, the resulting morphology in the nanoparticle synthesized via miniemulsion is almost always reported to form a core-shell structure with a fullerene-rich core. ${ }^{29,34-38}$ This nanostructure has been attributed to the higher surface energy of fullerene derivatives ( $P C_{61} B M-38.2 \mathrm{~mJ} \mathrm{~m}^{-2}$ and $\mathrm{PC}_{71} \mathrm{BM}-39 \mathrm{~mJ} \mathrm{~m}^{-2}$ ) compared to polymeric donors, but has been shown to be problematic for achieving high device performances. ${ }^{39}$ Variations in the donor polymer materials have been unsuccessful in altering this nonoptimal morphology, as the surface energies cannot approach those of the extremely high values characteristic of nanospherical fullerene materials. Indeed, these low surface energies could be considered as a roadblock for the rational design of organic blended nanoparticles. Some reports provide evidence for the nature of the surfactant playing a role in the resulting morphology of organic nanoparticles. In particular, using sodium 2-(3-thienyl)ethyloxybutylsulfonate (TEBS) instead of sodium dodecyl sulfate (SDS), Subianto et al. ${ }^{40}$ and Kosco et al. ${ }^{41}$ reported that a core-shell morphology for P3HT:PC ${ }_{61} B M$ nanoparticles and PTB7-Th:eh-IDTBR nanoparticles, respectively, was changed to a mixture of donorrich and acceptor-rich interspersed nano-domains. This change was attributed to the similarity in chemical structure of the TEBS surfactant to both donor and acceptor material, and also chloroform/water interfacial tensions which are equal when the chloroform phase contains the donor or the acceptor leading to the migration of both donor and acceptors at the water/chloroform interface (shell). Although playing with the interfacial tension is a good strategy to attain the desired initial particle morphology, overall it might not be thermodynamically favorable as the surface energy mismatch of the donor and acceptor components would lead to, upon thermal treatment of a nanoparticle film in a device, larger phase separation.

Indeed, the great interest in the field of organic semiconductor nanoparticles has led to recent reviews of the field, ${ }^{42}$ covering both nanoprecipitation and miniemulsion nanoparticle synthesis methods. As well as extensive studies focused on modelling the range of potential morphologies available from organic semiconductor nanoparticle systems. ${ }^{43}$

With the emergence of NFAs, the available synthetic chemistry routes to modify the molecular structure, and as a consequence the surface energy, is far greater than for fullerene derivatives. Thus, these NFAs form an ideal set of molecules to investigate how modifications to the surface chemistry of the acceptors can change nanoparticle formation thermodynamics; and consequently the charge carrier kinetics and electronic functionality of blended nanoparticle inks. With this wide range of acceptor materials, it is possible to investigate how to combine the established green ink processability of aqueous nanoparticles ${ }^{44}$ with the ability to engineer truly customized nanostructures. ${ }^{45}$ Such nanoengineered NFA blends offer an attractive option for the field of printed electronics and developing new fundamental 
physical chemistry insights into nanoscale structure-property relationships.

In this work, we provide the first in-depth study of the selforganization of various kinds of composite organic semiconductor nanoparticles as a function of their surface energy (the interfacial free energy of a surface). Two polymeric donors (TQ1 and P3HT) were combined with different types of molecular and polymeric NFAs (PNDIT10, N2200, o-IDTBR, ehIDTBR), and a wide range of techniques were used to elucidate the nanostructure of the resultant nanoparticles: transmission electron microscopy (TEM), scanning electron microscopy (SEM), near edge $X$-ray absorption fine structure (NEXAFS) spectroscopy and scanning transmission $X$-ray microscopy (STXM). The external shape obtained for all particles was found to be mainly driven by the semi-crystalline properties of the donor polymer. Nanoparticles including P3HT present a wrinkled texture while those prepared with amorphous TQ1 present a smoother texture. The internal composition of the nanoparticles was elucidated by STXM - the analysis of the different STXM compositional maps shows that the outer region of the particle (shell) is predominantly composed of the lowest surface energy materials. Indeed, through the variation of the NFA surface energies across a wide range (18.3 to $30.1 \mathrm{~mJ} \mathrm{~m}^{-2}$ ), we are able to demonstrate for the first time that the internal nanoscale structure of the nanoparticles is directly correlated to the surface energy differential between the blend materials for a comprehensive set of material systems. This general trend of the self-organization defines a critical new design rule for directing the morphology of organic semiconductor nanoparticles into desired structures. The ability to control the functionality of organic nanoparticle inks through chemical synthesis pathways to tuning the nanoparticle structure provides an invaluable new tool across a wide range of research applications.

\section{Experimental}

\section{Materials}

Poly $\left\{\left[N, N^{\prime}-\right.\right.$ bis(2-octyldodecyl)naphthalene-1,4,5,8bis(dicarboximide)-2,6-diyl]-alt-5,5'-(2,2'-bithiophene)\} (N2200) (also named PNDI(2OD)2T) was purchased from Ossila $\left(\mathrm{M}_{\mathrm{n}} 150,500 \mathrm{Da}\right.$, size dispersity (Đ) 1.93). Poly\{\{[N,N'-bis(2octyldodecyl)naphthalene-1,4,5,8-bis(dicarboximide)-2,6-diyl]alt-5,5'-(2,2'-bithiophene) $\}$-ran- $\left\{\left[\mathrm{N}, \mathrm{N}^{\prime}\right.\right.$-bis(2-

octyldodecyl)naphthalene-1,4,5,8-bis(dicarboximide)-2,6-diyl]alt-2,5-thiophene\}\} (PNDIT10) was purchased from Ossila $\left(\mathrm{M}_{\mathrm{n}}\right.$ 78,960 Da and $Ð$ 2.40). o-IDTBR and eh-IDTBR were purchased from 1-Materials. TQ1 ( $\left.M_{n} 53,100 \mathrm{Da}, \oplus 2.5\right)$ was synthesized by the copolymerization of monomers 5,8-dibromo-6,7-difluoro2,3-bis(3-(octyloxy)phenyl) quinoxaline and 2,5bis(trimethylstannanyl)thiophene, with the procedure described in detail elsewhere. ${ }^{34,46}$ Poly(3-hexylthiophene) (P3HT) was synthesized as described by Holmes et al. ${ }^{35}$ The chemical structures of the two polymer donor materials and four NFA materials are provided in Figure 2b. Sodium dodecy sulfate (SDS) surfactant and chloroform solvent were purchased from Sigma-Aldrich.

The surface energy of PNDIT10 was measured via optical tensiometry. Thin films of PNDIT10 were prepared on freshly cleaned and plasma treated microscope slides $(10 \mathrm{mg} / \mathrm{mL}$ solution in chloroform, $3000 \mathrm{rpm}, 30 \mathrm{~s}$, no annealing). The measurements were performed on a Biolin Scientific Attension Theta Optical Tensiometer. $2 \mu \mathrm{L}$ of liquid was manually deposited onto the film with a gas chromatography syringe, and video footage recoded at 12 frames per second for the duration of the measurement. Contact angles were fitted with the Young-Laplace expression. Diiodoethane $\left(\mathrm{Cl}_{2} \mathrm{H}_{2}, 99 \%\right.$ stored over $\mathrm{Cu}$ stabilizer, Sigma-Aldrich) and freshly prepared milli-Q $\mathrm{H}_{2} \mathrm{O}$ (resistivity $>18.3 \mathrm{M} \Omega \mathrm{cm}$ ) were used for contact angle measurements on the polymer films. The tensiometer was calibrated with a $4000 \pm 1.0 \mu \mathrm{m}$ standard tungsten carbide precision calibration ball. Measurements were performed at 22 ${ }^{\circ} \mathrm{C}$ at $30 \% \mathrm{RH}$ and ran in triplicate.

\section{Nanoparticle Synthesis}

The miniemulsion organic phase ("oil" phase) was prepared by dissolving $15 \mathrm{mg}$ of donor material (P3HT or TQ1) and $15 \mathrm{mg}$ of acceptor material (PNDIT10 or N2200) for 1:1 donor:acceptor systems, or $20 \mathrm{mg}$ of donor material and $10 \mathrm{mg}$ of acceptor material for 2:1 donor:acceptor systems, in $1.08 \mathrm{~mL}$ chloroform. The volume of organic solvent was increased to $1.62 \mathrm{~mL}$ for the donor:acceptor systems incorporating N2200, due to the large molecular weight of $\mathrm{N} 2200$ and the associated high viscosity solution. Note here that to generate the waterborne nanoparticle inks, organic solvent is used in the miniemulsion oil phase, but importantly, only a small volume is used, and this small volume of solvent is removed via evaporation such that later use of the inks in applications such as solar cell printing, do not involve organic solvents. In future large-scale nanoparticle synthesis, the chloroform can be substituted for a nonchlorinated oil phase solvent such as toluene or xylene. Also, the organic solvent can be reused in a closed synthesis cycle. The miniemulsion aqueous phase was prepared by dissolving $0.5 \mathrm{mg}$ of SDS surfactant in $2.8 \mathrm{~mL}$ of Milli- ${ }^{\circledR}{ }^{\circledR}$ filtered water. The surfactant concentration was purposely low so as to achieve a broad distribution in nanoparticle sizes for X-ray mapping experiments. Macroemulsions were generated by combining the organic and aqueous phases and stirring at $1100 \mathrm{rpm}, 33^{\circ} \mathrm{C}$ for $1 \mathrm{~h}$. A miniemulsion was generated using ultrasonication via a Hielscher UP400S ultrasonic processor with a $7 \mathrm{~mm}$ diameter tip. Sonication was at $30 \mathrm{~W}$ for $2 \mathrm{~min}$, with an amplitude setting of $50 \%$, an ice bath was used to prevent overheating of the sample. Following sonication, the miniemulsion was transferred immediately to a hot plate for organic solvent evaporation at 60 ${ }^{\circ} \mathrm{C}$ with rapid stirring. This evaporation was performed for a minimum of $3 \mathrm{~h}$ to ensure complete removal of organic solvent. The total volume of the nanoparticle inks was reduced to $0.5 \mathrm{~mL}$ via centrifugal dialysis. P3HT:eh-IDTBR nanoparticles were also synthesized via the nanoprecipitation method. A tetrahydrofuran (THF) solution of P3HT:eh-IDTBR was prepared at a total concentration of $5 \mathrm{mg} / \mathrm{mL}$ and a donor:acceptor ratio 
of $1: 1$. The THF solution was stirred at $60{ }^{\circ} \mathrm{C}$ for $2 \mathrm{~h}$ and then kept at $55{ }^{\circ} \mathrm{C}$. For the non-solvent phase, $4.5 \mathrm{~mL}$ of deionized water was added to a $6 \mathrm{~mL}$ vial and heated at $55{ }^{\circ} \mathrm{C}$ under moderate stirring (300 rpm). $0.5 \mathrm{~mL}$ of THF solution was inserted quickly into the water containing vial. The dispersion was removed from the hot plate and cooled down at room temperature for $10 \mathrm{~min}$, then subsequently filtered with a $5 \mu \mathrm{m}$ filter. An additional evaporation step was applied, to evaporate the THF the dispersion was left stirring at $300 \mathrm{rpm}$ on a hot plate at $60{ }^{\circ} \mathrm{C}$ for $3 \mathrm{~h}$ with the lid open.

\section{NEXAFS Spectroscopy}

NEXAFS measurements of TQ1, P3HT, N2200, PNDIT10 and oIDTBR were performed on beamline 5.3.2.2 at the Advanced Light Source (ALS) synchrotron in Berkeley, California. Pristine films of TQ1, P3HT, N2200, PNDIT10, O-IDTBR and eh-IDTBR were prepared by spin coating chloroform solutions of each semiconductor material onto PEDOT:PSS (Clevios P VP Al 4083, purchased from H.C. Starck) coated glass substrates. $2 \times 2 \mathrm{~mm}^{2}$ sections were scored on the films using a scalpel, followed by floating off the film sections onto a D.I. water surface, which was made possible by dissolving the PEDOT:PSS sacrificial layer under the semiconductor material films. $2 \times 2 \mathrm{~mm}^{2}$ film sections were subsequently collected onto 300 mesh $\mathrm{Cu}$ grids $(20 \mu \mathrm{m}$ bar, $63 \mu \mathrm{m}$ hole, $3 \mathrm{~mm}$ diameter, purchased from ProSciTech Pty Ltd) for NEXAFS measurements. The energy of the X-ray beam was varied between 270 and $340 \mathrm{eV}$, spanning the $\mathrm{C} \mathrm{K}$ edge region with an energy resolution of $0.1 \mathrm{eV}$. Second- and third- order light was removed by an order sorting aperture and also an $\mathrm{N}_{2}$ gas filter (further details are provided in Kilcoyne et al. ${ }^{47}$ ). Energy calibration at the $\mathrm{C}$ K-edge was performed using $\mathrm{CO}_{2}$ gas (peak at $292.74 \mathrm{eV}$ ).

NEXAFS measurements of eh-IDTBR were performed on the PolLux beamline (XO7DA) at the Swiss Light Source (SLS) synchrotron, with similar measurement parameters to those used at the ALS. The energy of the X-ray beam was varied between 270 and $340 \mathrm{eV}$, spanning the $\mathrm{C} K$-edge region with an energy resolution of $0.15 \mathrm{eV}$. Dwell times were increased to 10 and $12 \mathrm{~ms}$ to account for lower flux at SLS PolLux compared to ALS 5.3.2.2.

Orthogonal energies were determined from NEXAFS spectra of pristine films of P3HT, TQ1, PNDIT10, N2200, o-IDTBR and ehIDTBR.

\section{X-ray Spectromicroscopy}

X-ray spectromicroscopy (STXM) measurements were performed on beamline 5.3.2.2 at the ALS synchrotron. Samples were prepared for STXM measurements by spin coating $2.5 \mu \mathrm{L}$ of nanoparticle ink onto low stress silicon nitride $\left(\mathrm{Si}_{3} \mathrm{~N}_{4}\right)$ membrane windows with silicon dioxide coating (window dimensions $0.25 \times 0.25 \mathrm{~mm}^{2}$, window thickness $15 \mathrm{~nm}$, silicon frame dimensions $5 \times 5 \mathrm{~mm}^{2}$, purchased from Norcada, Canada) at $3000 \mathrm{rpm}, 1 \mathrm{~min}$, low acceleration of $112 \mathrm{rpm} / \mathrm{s}$. Samples were air dried at room temperature. The samples on $\mathrm{Si}_{3} \mathrm{~N}_{4}$ windows were loaded in the STXM sample chamber and rastered with respect to the X-ray beam. The STXM sample chamber was backfilled with helium (0.33 atm). The transmitted $\mathrm{X}$-ray beam is detected by a scintillator and a photomultiplier tube. The STXM Fresnel zone plate had an outer most zone width of $25 \mathrm{~nm}$, setting the spatial resolution limit of the measurement. Singular value decomposition (SVD) was used to fit a sum of the pristine material NEXAFS spectra to the measured blend spectrum of the nanoparticles - at each pixel in the STXM images. Prior to SVD fitting, the pristine material NEXAFS spectra are normalized to film thickness. The method of reference-spectrum normalization constitutes dividing the real spectrum by a theoretical spectrum calculated based on the material's chemical formula using henke.lbl.gov/optical_constants/filter.html. The aXis2000 package was used to perform image analysis of STXM maps.

\section{Electron Microscopy}

TEM was used to reimage the same nanoparticles, where possible, for collecting position-matched micrographs. The $\mathrm{Si}_{3} \mathrm{~N}_{4}$ substrates with deposited nanoparticles were transported back to the University of Newcastle (Australia) to measure TEM on a JEOL 1200 EXII at an accelerating voltage of $80 \mathrm{kV}$ at varying magnification ranges.

Samples were prepared for SEM by spin coating $2.5 \mu \mathrm{L}$ of the nanoparticle inks (3000 rpm, $1 \mathrm{~min}$, low acceleration of 112 $\mathrm{rpm} / \mathrm{s}$ ) onto highly doped silicon substrates (Type $\mathrm{P}$ (boron), $<111>$, resistance of $1-30 \Omega$, roughness of $2 \mathrm{~nm}$, purchased from ProSciTech Pty Ltd). The silicon substrates were first UVozone cleaned for $10 \mathrm{~min}$. SEM was performed on a Zeiss Sigma VP FESEM operating at an accelerating voltage of $2 \mathrm{kV}$.

\section{Results and Discussion}

\section{Materials Selection and Surface Energy}

Two polymeric donors (TQ1 and P3HT), two polymeric NFAs (N2200, PNDIT10) and two small molecule NFAs (o- and ehIDTBR) were chosen for this study. We took advantage of the new range of low bandgap NFAs with desirable properties such as tunable bandgap and broad light absorption. N2200 is a naphthalene diimide (NDI) based polymer, which provides high electron affinity, electron mobility, strong absorption in the visible and near-infrared region and good solubility. ${ }^{22}$ Critically, the imide functionality also produces a relatively low surface energy. PNDIT10 is a structural analogue of N2200 generated by replacing a number of bithiophene (2T) units in the N2200 backbone by single thiophene $(\mathrm{T})$ units, where $\mathrm{T} 10$ represents the percentage of the single $T$ at $10 \% .{ }^{22}$ PNDIT10 has a more flexible backbone and lower crystallinity than N2200 due to its reduced regularity in the main chain, which also modulates the surface energies to higher values. ${ }^{22}$ IDTBR derivatives have been employed in this study as additional NFAs with variable surface energies. IDTBR acceptors were developed by Holliday et al. in $2016,{ }^{21}$ and consist of side-chain engineering from a common core, with a linear ( $\mathrm{n}$-octyl) alkyl chain generating the molecule o-IDTBR, yielding a higher surface energy crystalline material, while the branched 2-ethylhexyl side-chain structural analogue 
(eh-IDTBR) has a lower surface energy and is mostly amorphous. ${ }^{21}$

The key material properties utilized to select an acceptor material for OPV fabrication, namely HOMO, LUMO, $E_{g}, \lambda_{\max }$, are listed in Table 1, with the UV-Vis absorbance spectra provided in Figure S1 (Supplementary Material). The selection of materials for this study was aimed at understanding the influence of physico-chemical properties, such as surface energy, on the donor-acceptor nanoparticle morphology, hence the surface energy of the acceptor ranges from 18.3 to $30.1 \mathrm{~mJ}$ $\mathrm{m}^{-2}$ (Table 1).

Table 1 - Surface energy, HOMO, LUMO, optical bandgap $\left(\mathrm{E}_{\mathrm{g}}\right)$ and $\lambda_{\max }$ of donor and acceptor materials.

\begin{tabular}{|c|c|c|c|c|}
\hline Material & HOMO / LUMO (eV) & $E_{g}(e V)$ & $\lambda_{\max }(\mathrm{nm})$ & $\begin{array}{c}\text { Surface Energy } \\
\left(\mathrm{mJ} \mathrm{m}^{-2}\right)\end{array}$ \\
\hline \multicolumn{5}{|c|}{ Donor } \\
\hline TQ1 & $-5.7 /-3.3^{46}$ & $1.7^{46}$ & $362,622^{a}$ & 2948 \\
\hline P3HT & $-5.2 /-3.2^{55}$ & $1.9^{56}$ & $522^{a}$ & $26.9^{49}$ \\
\hline \multicolumn{5}{|c|}{ Non-fullerene acceptor } \\
\hline PNDIT10 & $-6.36 /-4.05^{22}$ & $1.55^{22}$ & $344,600^{\text {a }}$ & 30.1 \\
\hline N2200 & $-6.26 /-4.06^{22}$ & $1.44^{22}$ & $393,703^{a}$ & $23.7^{50,51}$ \\
\hline o-IDTBR & $-5.51 /-3.88^{21}$ & $1.63^{21}$ & $690^{a}$ & $28.1^{52}$ \\
\hline eh-IDTBR & $-5.58 / 3.90^{21}$ & $1.68^{21}$ & $672^{a}$ & $18.3^{53}$ \\
\hline \multicolumn{5}{|c|}{ Fullerene acceptor (for comparison purposes) } \\
\hline $\mathrm{PC}_{61} \mathrm{BM}$ & $-5.80 /-3.80^{57}$ & $2.0^{b}$ & $350^{58}$ & $38.2^{59}$ \\
\hline $\mathrm{PC}_{71} \mathrm{BM}$ & $-5.9 /-3.7^{60}$ & $2.2^{b}$ & $475^{34}$ & 3948 \\
\hline
\end{tabular}

a Supplementary Material

${ }^{b}$ Electronic bandgap (determined from UPS/IPES), whereas for all other materials the optical bandgap is listed.

Conveniently, the similarity of the structural analogs selected (N2200 and PNDIT10; o-IDTBR and eh-IDTBR) also enabled an investigation of the impact of material crystallinity on the selfassembly of the nanoparticles. With the exception of the NFA polymer PNDIT10, the surface energy of the polymers and small molecules used in nanoparticle synthesis are found in the literature. ${ }^{48-53}$ We characterized the surface energy of PNDIT10 using Fowkes' Theory ${ }^{54}$ and the two-drop method to be $30.1 \mathrm{~mJ}$ $\mathrm{m}^{-2}$, largely dominated by the dispersive contribution (see Table 1 and Supplementary Material).

\section{Nanoparticle Synthesis and Electron Microscopy}

Two component nanoparticles were synthesized via the miniemulsion method for the donor-acceptor material systems TQ1:N2200, TQ1:PNDIT10, P3HT:N2200, P3HT:O-IDTBR and P3HT:eh-IDTBR. A 1:1 w/w ratio was applied to all systems, with the exception of the TQ1:N2200 system where both a 1:1 and a $2: 1 \mathrm{w} / \mathrm{w}$ ratio were studied. For the P3HT:eh-IDTBR system, nanoparticles were also synthesized via the nanoprecipitation method, and both miniemulsion nanoparticles and nanoprecipitation nanoparticles were analyzed with STXM, Figure S4 and Figure 4k-n, respectively.

Prior to investigation of the nanoparticle internal structure for each system with synchrotron-based X-ray microscopy, SEM measurements of the nanoparticle samples were performed to assess the (1) shape and surface texture of the particles, (2) particle size and size distribution, and the (3) particle packing and film formation (Figure 1). P3HT:N2200 nanoparticles are angular, non-spherical in shape and possess a wrinkled surface texture (Figure 1d); attributed to the crystallinity of both P3HT and N2200 polymers. 22,32 The presence of crystalline P3HT domains in the P3HT:N2200 nanoparticles is further confirmed by the vibronic peaks ${ }^{61,62}$ at 560 and $610 \mathrm{~nm}$ in the UV-Vis absorbance spectrum of the nanoparticle ink (Figure S2). TQ1:PNDIT10 and TQ1:N2200 nanoparticles (both 1:1 and 2:1) are predominantly spherical in shape and smooth in texture (Figure 1a-c); TQ1 is an amorphous polymer combined with the semi-crystalline polymer N2200.63 PNDIT10 is also a semicrystalline polymer, but less crystalline than N2200.22 The P3HT:O-IDTBR and P3HT:eh-IDTBR nanoparticles are predominantly spherical in shape and wrinkled in texture (Figure 1e-f). o-IDTBR is a more crystalline material than ehIDTBR, ${ }^{21}$ combined with the crystalline polymer P3HT likely contributing to the wrinkled surface texture of the nanoparticles.

The particle size and size distribution for each nanoparticle sample is tabulated in Table 2, with the mean value used as an indicator of nanoparticle size and the standard deviation $(\sigma)$ used as an indicator of the size distribution. The nanoparticle size was measured by applying a circular Hough transform algorithm to SEM images of nanoparticle films, according to our previously reported method. ${ }^{34}$ This method gave diameters of $233 \pm 105 \mathrm{~nm}$ for the TQ1:PNDIT10 nanoparticles; $172 \pm 74 \mathrm{~nm}$ for the 1:1 TQ1:N2200 nanoparticles; and $139 \pm 50 \mathrm{~nm}$ for the 2:1 TQ1:N2200 nanoparticles. For the nanoparticles synthesized with $\mathrm{P} 3 \mathrm{HT}$ donor material, the Hough transform analysis gave diameters of $212 \pm 81 \mathrm{~nm}$ for the P3HT:O-IDTBR nanoparticles and $170 \pm 89 \mathrm{~nm}$ for the P3HT:eh-IDTBR nanoparticles. The P3HT:N2200 nanoparticle diameter of $233 \pm 132 \mathrm{~nm}$ listed in Table 2 represents the particle length, as these nanoparticles were not spherical and hence the circular Hough transform 

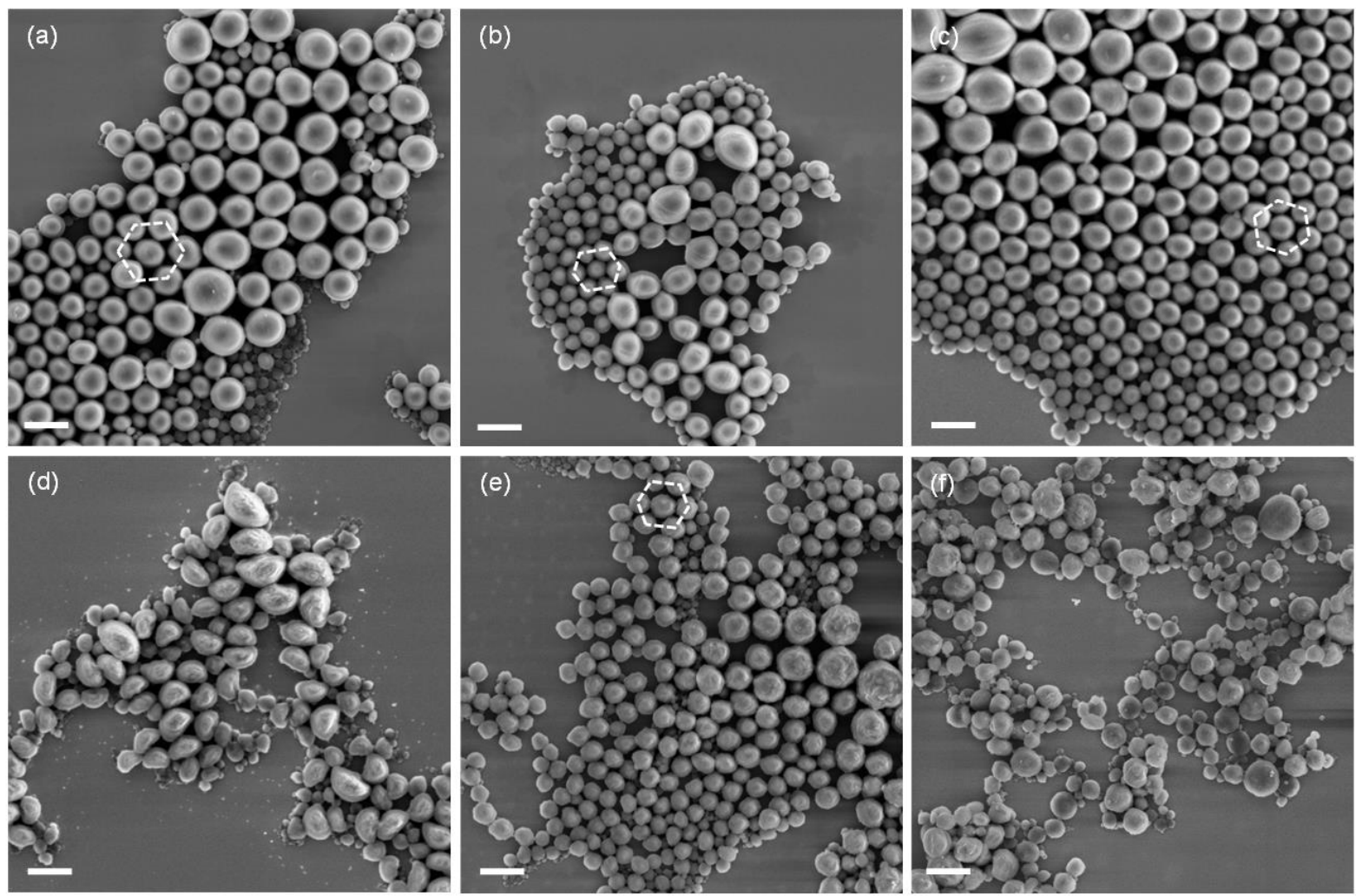

Figure 1 - SEM of (a) 1:1 TQ1:PNDIT10 nanoparticles, (b) 1:1 TQ1:N2200 nanoparticles, (c) 2:1 TQ1:N2200 nanoparticles, (d) 1:1 P3HT:N2200 nanoparticles, (e) 1:1 P3HT:O-IDTBR nanoparticles, and (f) 1:1 P3HT:eh-IDTBR nanoparticles. Scale bar is $500 \mathrm{~nm}$. Examples of HCP are identified in

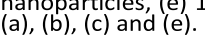

MATLAB code was not suitable. The particle sizes reported in Table 2 have been customized to optimize STXM imaging.

The particle packing and film formation can be easily visualized in the SEM in Figure 1. Regions of randomly close packed $(R C P)^{64,65}$ arrays are evident in all six film types. Regions of hexagonally close packed (HCP) ${ }^{66}$ arrays are more common in samples which are more monodisperse, that is, have a narrow size distribution and predominantly spherical particles. There is evidence of HCP arrays in the TQ1:PNDIT10, 1:1 TQ1:N2200, 2:1
TQ1:N2200 and P3HT:O-IDTBR nanoparticle samples (Figure $1 a, b, c$ and e).

\section{NEXAFS Spectroscopy of NFAs, Orthogonal Energy Identification for STXM}

NEXAFS spectra were collected in transmission mode at the ALS synchrotron on beamline 5.3.2.2, and at the SLS synchrotron on the PolLux beamline (X07DA) for material eh-IDTBR. Figure 2

Table 2 - Nanoparticle properties: Shape and surface texture; nanoparticle size (calculated using circular Hough transform analysis of SEM images, $>1200$ nanoparticles sampled for each material system); nanoparticle film packing classification.

\begin{tabular}{|c|c|c|c|}
\hline Donor-Acceptor System & Shape / Surface Texture & $\begin{array}{l}\text { Nanoparticle Diameter (Mean } \pm \sigma) \\
(\mathrm{nm})\end{array}$ & Packing Classification \\
\hline \multicolumn{4}{|c|}{ NFAs combined with TQ1 donor } \\
\hline 1:1 TQ1:PNDIT10 & Predominantly spherical / Smooth & $233 \pm 105$ & $\mathrm{HCP}, \mathrm{RCP}$ \\
\hline 1:1 TQ1:N2200 & Predominantly spherical ${ }^{\mathrm{d}}$ / Smooth & $172 \pm 74$ & $\mathrm{HCP}, \mathrm{RCP}$ \\
\hline 2:1 TQ1:N2200 & Predominantly spherical ${ }^{\mathrm{d}} /$ Smooth & $139 \pm 50$ & $\mathrm{HCP}, \mathrm{RCP}$ \\
\hline \multicolumn{4}{|c|}{ NFAs combined with P3HT donor } \\
\hline 1:1 P3HT:N2200 & Angular \& non-spherical / Wrinkled & $233 \pm 132^{c}$ & $\mathrm{RCP}$ \\
\hline 1:1 P3HT:o-IDTBR & Predominantly spherical / Wrinkled & $212 \pm 81$ & $\mathrm{HCP}, \mathrm{RCP}$ \\
\hline 1:1 P3HT:eh-IDTBR & Predominantly spherical / Wrinkled & $170 \pm 89$ & RCP \\
\hline
\end{tabular}

c The P3HT:N2200 nanoparticles were not spherical, hence the diameter value represents the particle length.

d Some instances of prolate spheroids. 

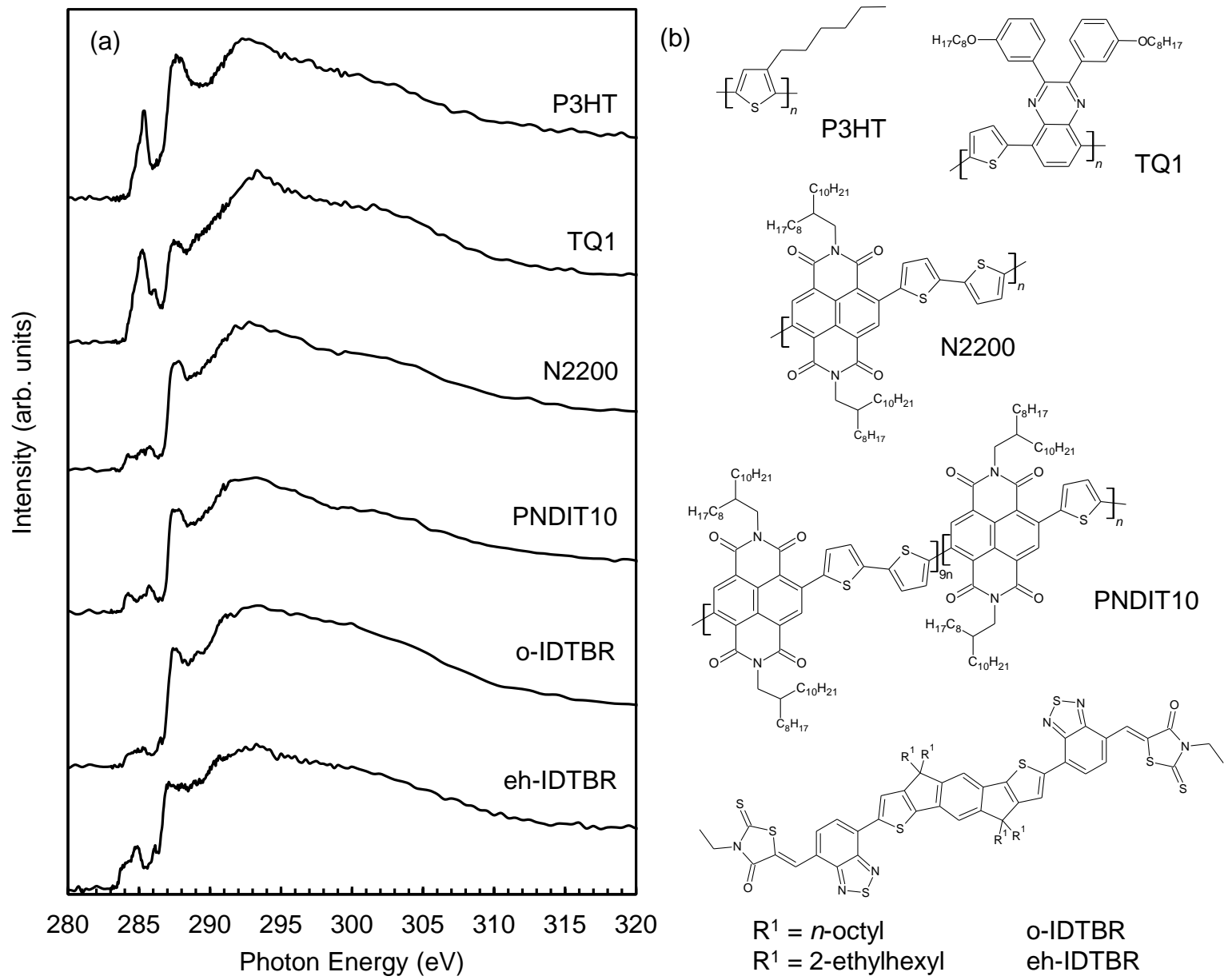

Figure 2 - (a) NEXAFS spectra and (b) chemical structures of donor materials P3HT and TQ1; and non-fullerene acceptor materials N2200, PNDIT10, o-IDTBR and eh-IDTBR.

presents the NEXAFS spectra of donor polymers TQ1 and P3HT, and the NFA materials N2200, PNDIT10, o-IDTBR and eh-IDTBR. STXM (a spatially-resolved variant of transmission NEXAFS spectroscopy) ${ }^{47}$ was utilized as a high-resolution imaging technique with chemical sensitivity to collect X-ray maps of nanoparticle films at multiple photon energies of the incident beam. A careful selection of the photon energy for each X-ray map was performed, establishing the orthogonal energies, and singular value decomposition (SVD) employed to determine the relative ratio of components (at each pixel) for a blend film. 65 Orthogonal energies were chosen prior to collecting X-ray maps by directly comparing the NEXAFS spectra of pristine films of each of the blend film components and finding specific energies with a marked difference in X-ray absorption for each of the component materials. The orthogonal energies selected for STXM analysis are listed in Table S1, and further detail of optimizing measurement conditions for these polymerdonor:NFA systems is provided in Supplementary Material.

\section{Nanoparticle Structure via Self-Assembly}

STXM measurements were carried out using beamline 5.3.2.2 at the ALS synchrotron to ascertain the internal nanostructure of the donor-acceptor nanoparticles. STXM composition maps were collected, together with position-matched TEM, for 1:1 TQ1:PNDIT10, 1:1 TQ1:N2200, 2:1 TQ1:N2200 (Figure 3) and 1:1 P3HT:N2200, 1:1 P3HT:o-IDTBR, 1:1 P3HT:eh-IDTBR (Figure 4) nanoparticles. As will be discussed in detail shortly, a core-shell structure was measured for all donor-acceptor systems studied, and so the STXM compositional maps were utilized to calculate the donor and acceptor material concentrations in the nanoparticle shell and core domains. STXM is a transmission technique, hence the nanoparticle core compositions were calculated by subtracting the nanoparticle shell contribution from the composition at the nanoparticle centre (with the full method reported elsewhere in the literature ${ }^{35}$ ). A typical radial profile of a nanoparticle synthesized for each material system is plotted in Figure 5 (with detail on the method for deriving radial profiles provided in Supplementary Material), and the composition of the nanoparticle core and shell domains for each material system studied is listed in Table 3.

A core-shell structure was measured for all six nanoparticle types studied with STXM, with the shell and core composition varying depending on the donor-acceptor material combination. The core-shell structure was derived from the 

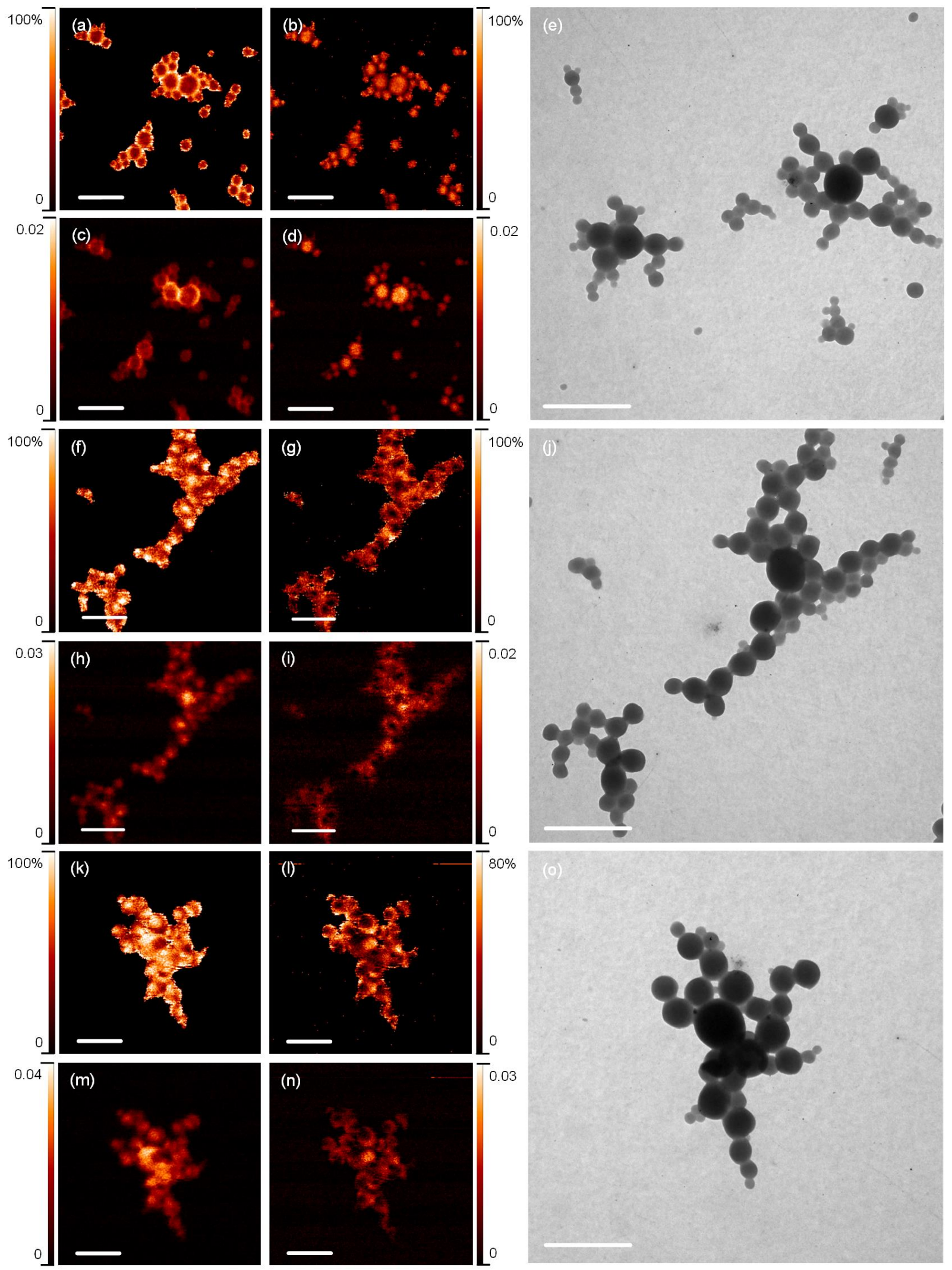

Figure 3 - STXM fractional composition maps showing the concentration of (a) TQ1 and (b) PNDIT10 with corresponding STXM mass plots (c and d) and (e) TEM for 1:1 TQ1:PNDIT10 nanoparticles; STXM fractional composition maps showing the concentration of (f) TQ1 and (g) N2200 with corresponding STXM mass plots ( $\mathrm{h}$ and i) and (j) position-matched TEM for 1:1 TQ1:N2200 nanoparticles; STXM fractional composition maps showing the concentration of (k) TQ1 and (I) N2200 with corresponding STXM mass plots ( $m$ and $n$ ) and (o) position-matched TEM for 2:1 TQ1:N2200 nanoparticles. All scale bars are $1 \mu \mathrm{m}$. The colour contrast is scaled such that light colours correspond to higher component concentrations. For the mass plots (c, $d, h$, $i, m, n)$ the colour scale bars indicate concentration of component in $\mathrm{mg} \mathrm{cm}^{-2}$. 

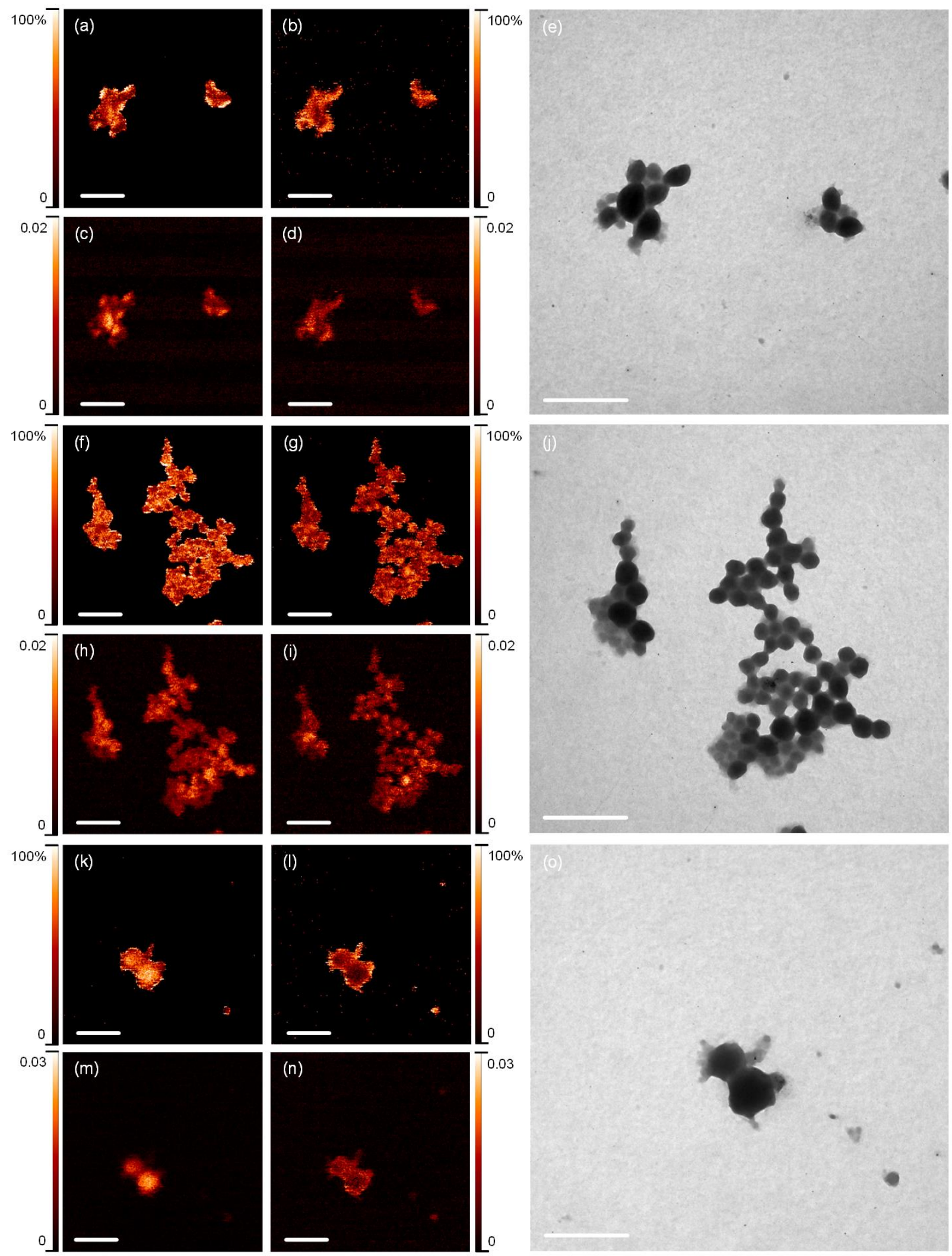

Figure 4 - STXM fractional composition maps showing the concentration of (a) P3HT and (b) N2200 with corresponding STXM mass plots (c and d) and (e) position-matched TEM for 1:1 P3HT:N2200 nanoparticles; STXM fractional composition maps showing the concentration of (f) P3HT and (g) o-IDTBR with corresponding STXM mass plots ( $\mathrm{h}$ and $\mathrm{i}$ ) and (j) position-matched TEM for 1:1 P3HT:o-IDTBR nanoparticles; STXM fractional composition maps showing the concentration of $(\mathrm{k})$ P3HT and (I) eh-IDTBR with corresponding STXM mass plots ( $\mathrm{m}$ and $\mathrm{n}$ ) and (o) position-matched TEM for 1:1 P3HT:eh-IDTBR nanoparticles (nanoprecipitation). All scale bars are $1 \mu \mathrm{m}$. The colour contrast is scaled such that light colours correspond to higher component concentrations. For the mass plots $(c, d, h, i, m, n)$ the colour scale bars indicate concentration of component in $\mathrm{mg} \mathrm{cm}^{-2}$. 
Table 3 - Compositional analysis of donor-acceptor nanoparticles, as calculated from STXM maps. On average, 15 nanoparticles per material system were analyzed in order to extract the compositions listed in this table.

\begin{tabular}{|c|c|c|c|c|c|}
\hline \multirow{2}{*}{$\begin{array}{c}\text { Donor-Acceptor } \\
\text { System }\end{array}$} & \multirow{2}{*}{$\begin{array}{l}\text { Morphology } \\
\text { Classification }\end{array}$} & \multicolumn{2}{|c|}{ Nanoparticle Shell } & \multicolumn{2}{|c|}{ Nanoparticle Core } \\
\hline & & $\begin{array}{c}\text { Predominant } \\
\text { Shell Component }\end{array}$ & 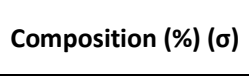 & $\begin{array}{c}\text { Predominant } \\
\text { Core Component }\end{array}$ & 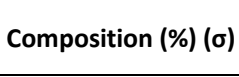 \\
\hline \multicolumn{6}{|c|}{ NFAs combined with TQ1 donor } \\
\hline 1:1 TQ1:PNDIT10 & $\begin{array}{l}\text { Core-shell } \\
\text { (NFA core) }\end{array}$ & TQ1 & $\begin{array}{c}\text { TQ1: } 80(4) \\
\text { PNDIT10: } 20(4)\end{array}$ & PNDIT10 & $\begin{array}{c}\text { TQ1: } 16(9) \\
\text { PNDIT10: } 84(9)\end{array}$ \\
\hline 2:1 TQ1:N2200 & $\begin{array}{l}\text { Core-shell } \\
\text { (NFA shell) }\end{array}$ & N2200 & $\begin{array}{c}\text { TQ1: } 47(5) \\
\text { N2200: } 53(5)^{\mathrm{e}}\end{array}$ & TQ1 & $\begin{array}{c}\text { TQ1: } 87 \text { (9) } \\
\text { N2200: } 13 \text { (9) }\end{array}$ \\
\hline \multicolumn{6}{|c|}{ NFAs combined with P3HT donor } \\
\hline 1:1 P3HT:N2200 & $\begin{array}{l}\text { Core-shell } \\
\text { (NFA shell) }\end{array}$ & N2200 & $\begin{array}{c}\text { P3HT: } 39(7) \\
\text { N2200: } 61(7) \text { e }\end{array}$ & Р3HT & $\begin{array}{l}\text { P3HT: } 91(6) \\
\text { N2200: } 9(6)\end{array}$ \\
\hline 1:1 P3HT:eh-IDTBR ${ }^{f}$ & $\begin{array}{l}\text { Core-shell } \\
\text { (NFA shell) }\end{array}$ & eh-IDTBR & $\begin{array}{c}\text { P3HT: } 29(6) \\
\text { eh-IDTBR: } 71(6)\end{array}$ & Р3HT & $\begin{array}{c}\text { P3HT: } 61 \text { (7) } \\
\text { eh-IDTBR: } 39(7)\end{array}$ \\
\hline
\end{tabular}

e While the TQ1:N2200 and P3HT:N2200 nanoparticles contain N2200-rich shells, the absolute N2200 content of these nanoparticles is close to 50\%, being due to the low solubility of the high molecular weight polymer batch $\left(M_{n} 150,500 \mathrm{Da}\right)$ in solvent. The low solubility of the high molecular weight $\mathrm{N} 2200$ batch also accounts for the minimal change in domain composition when the ratio of TQ1 to N2200 changes (and hence N2200 loading changes) when moving from the 2:1 sample to the 1:1 sample.

${ }_{\mathrm{f}}$ Composition values from nanoprecipitation-based nanoparticles, whereas for all other systems miniemulsion-based nanoparticle data is listed.
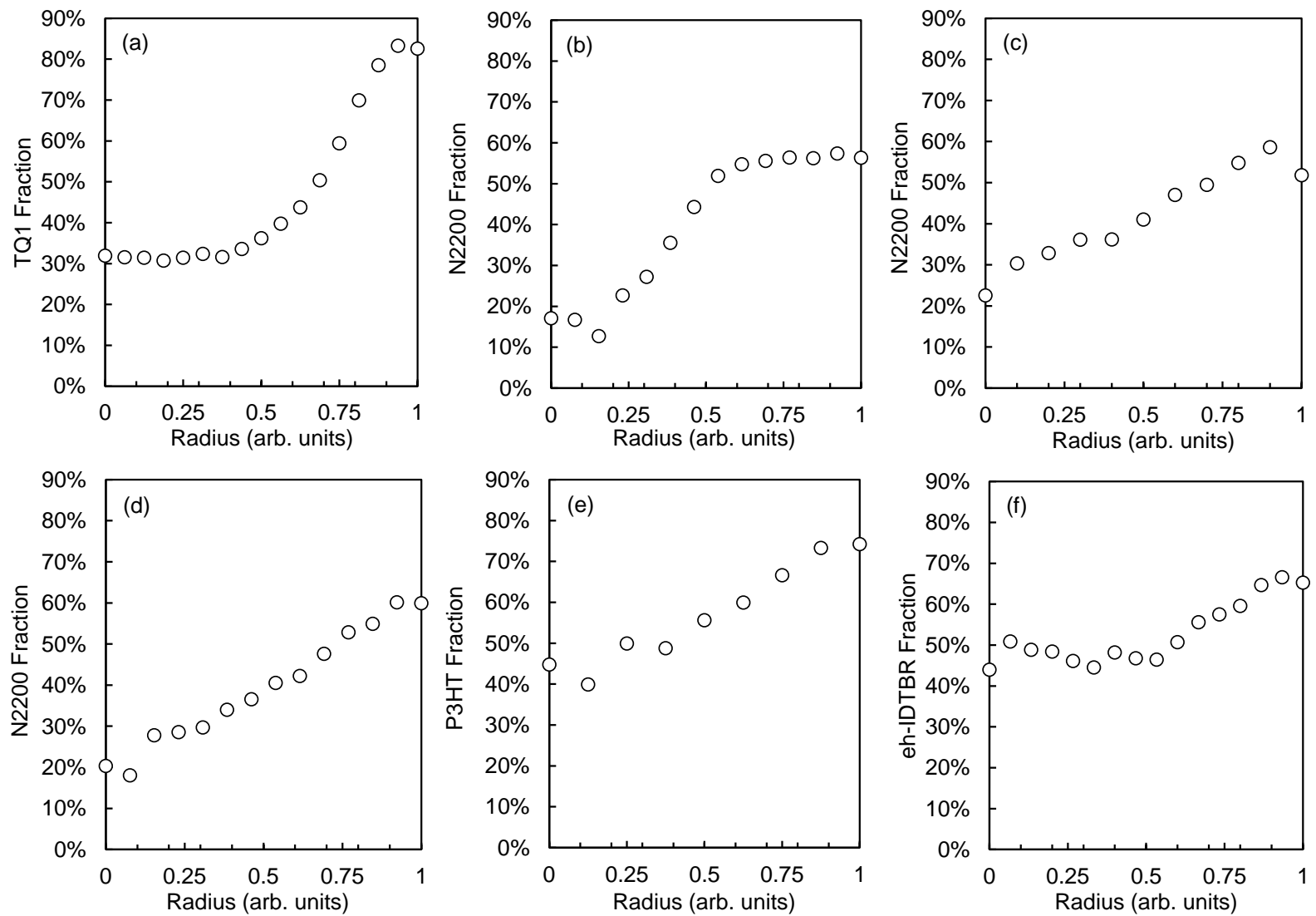

Figure 5 - A typical radial profile of a nanoparticle synthesized for the material system (a) TQ1:PNDIT10 (1:1), (b) TQ1:N2200 (1:1), (c) TQ1:N2200 (2:1), (d) P3HT:N2200 (1:1), (e) P3HT:o-IDTBR (1:1), and (f) P3HT:eh-IDTBR (1:1) (nanoprecipitation). Radial profiles were extracted from STXM fractional composition maps. Each data point represents a spatial distance of $16 \mathrm{~nm}$. 
STXM maps (Figure 3 and Figure 4) for each system by extracting the radial profiles of the nanoparticles (Figure 5), which show an increase of one component from particle centre to particle perimeter. For example, for TQ1:PNDIT10 nanoparticles, the TQ1 composition is low at the particle centre in Figure $5 \mathrm{a}$, but the TQ1 concentration increases to $>75 \%$ at the particle perimeter. This composition difference is also visibly evident in the STXM maps themselves, where a bright "ring" appears around the particles in Figure 3a for example, reflecting a high concentration of TQ1.

For the TQ1:NFA nanoparticle systems characterized via STXM, a TQ1-rich shell $(80 \pm 4 \%)$ and PNDIT10-rich core (84 \pm 9\%) was measured for the TQ1:PNDIT10 nanoparticles, as depicted in Figure 3a-e. For the TQ1:N2200 nanoparticles, the structure inverted to a TQ1-rich core for both 1:1 (Figure 3f-j) and 2:1 (Figure 3k-o) donor:acceptor ratios. An N2200-rich shell is evident by the bright rings observed in the N2200 STXM fractional composition map for the 1:1 (Figure 3g) and the 2:1 (Figure 3I) TQ1:N2200 nanoparticles. The composition was measured as $55 \pm 3 \%$ and $53 \pm 5 \%$ for the N2200-rich shells for the 1:1 and 2:1 TQ1:NN2200 nanoparticles, respectively, and the composition of the TQ1-rich cores was $92 \pm 5 \%$ and $87 \pm 9 \%$ for the 1:1 and 2:1 TQ1:N2200 nanoparticles, respectively.

Looking now at the P3HT:NFA nanoparticles characterized using STXM (as shown in Figure 4), the location of the P3HT in the nanoparticles flipped from core to shell - then back to core - as the NFA was changed from N2200 to o-IDTBR to eh-IDTBR. An N2200-rich shell (61 $\pm 7 \%)$ and P3HT-rich core (91 $\pm 6 \%)$ was measured for the P3HT:N2200 nanoparticles, as depicted in Figure 4a-e. For the P3HT:O-IDTBR nanoparticles, a P3HT-rich shell $(69 \pm 6 \%)$ and o-IDTBR-rich core $(74 \pm 16 \%)$ was measured (Figure $4 \mathrm{f}-\mathrm{j}$ ). For the IDTBR nanoparticle series, the IDTBR core inverts to an IDTBR-rich shell for the P3HT:eh-IDTBR nanoparticles synthesized via both nanoprecipitation (Figure $4 \mathrm{k}-\mathrm{o}$ ) and miniemulsion (Figure S4). A composition of $71 \pm 6 \%$ is measured for the eh-IDTBR-rich shells and a composition of 61 $\pm 7 \%$ is measured for the P3HT-rich cores.

We note that the nanoprecipitation method, compared to the miniemulsion method, has been previously reported to produce nanoparticles with a predominantly uniform phase separation. ${ }^{42,68-70}$ Our study constitutes the first report of the nanoscale morphology of P3HT:eh-IDTBR nanoparticles prepared from both the nanoprecipitation and the miniemulsion method, both being core-shell in nature. It is possible that for the nanoprecipitated P3HT:eh-IDTBR nanoparticles a uniform phase separation formed inititally, but then self-assembly to a core-shell structure occurred during the 3 hour $60^{\circ} \mathrm{C}$ THF solvent removal step (from the continuous aqueous phase), a temperature above the reported $\mathrm{T}_{\mathrm{g}}$ of $\mathrm{P} 3 \mathrm{HT}$.

Table 4 - Tabulated nanoparticle shell composition and surface energy differential for donor:NFA and donor:fullerene acceptor systems.

\begin{tabular}{|c|c|c|}
\hline Donor-Acceptor System & $\begin{array}{l}\text { Acceptor Composition in Nanoparticle Shell } \\
(\%)\end{array}$ & $\Delta \mathbf{G}_{\text {surface }}\left(\mathbf{G}_{\text {surface(acceptor) }}-\mathrm{G}_{\text {surface(donor) })}\left(\mathrm{mJ} \mathrm{m}^{-2}\right)\right.$ \\
\hline \multicolumn{3}{|c|}{ NFA acceptor } \\
\hline TQ1:PNDIT10 & $20(4)$ & 1.1 \\
\hline TQ1:N2200 & $55(3)$ & -5.3 \\
\hline P3HT:N2200 & $61(7)$ & -3.2 \\
\hline P3HT:O-IDTBR & $31(6)$ & 1.2 \\
\hline P3HT:eh-IDTBR g & $71(6)$ & -8.6 \\
\hline \multicolumn{3}{|c|}{ Fullerene acceptor (for comparison purposes) } \\
\hline $\mathrm{P} 3 \mathrm{HT}: \mathrm{PC}_{61} \mathrm{BM}$ & $30(1)^{37}$ & 11.3 \\
\hline TQ1:PC ${ }_{71} \mathrm{BM}$ & $22.5(8)^{34}$ & 10 \\
\hline
\end{tabular}

$\mathrm{g}$ Composition values from nanoprecipitation-based nanoparticles, whereas for all other systems miniemulsion-based nanoparticle data is listed.

\section{Correlation of Surface Energy to Morphology}

Previous studies of fullerene-containing systems have shown that the surface energy of different components in both bulk heterojunction blends ${ }^{71,72}$ and binary nanoparticles ${ }^{36}$ determines their segregation and location in the blend system. Although surface energy - morphology correlations have been commonly reported in the BHJ literature for many years, such a correlation has not been thoroughly investigated for nanoparticulate structures with a material sample set greater than two. And the BHJ system differs substantially to the nanoparticulate system, where the thermodynamics of the latter are complicated by the additional morphology consideration of kinetically stabilized waterborne nanoparticle formation. The core-shell formation reported in this study can be correlated to the relative surface energies of the donor and acceptor materials (listed in Table 1), where to minimize total energy the material with the lower surface energy migrates to the outer surface of the miniemulsion droplets during organic solvent evaporation and nanoparticle formation. For the TQ1:PNDIT10 nanoparticles, we observe a TQ1-rich shell and PNDIT10-rich core structure, as the surface energy of PNDIT10 is $30.1 \mathrm{~mJ} \mathrm{~m}^{-2}$ which is higher than that of TQ1 at $29 \mathrm{~mJ} \mathrm{~m}^{-2}$. For both the 1:1 and 2:1 w/w ratio TQ1:N2200 nanoparticles we observe a N2200-rich shell and TQ1-rich core, as TQ1 has a higher surface energy than $\mathrm{N} 2200\left(23.7 \mathrm{~mJ} \mathrm{~m}^{-2}\right)$. Similarly, the P3HT:N2200 nanoparticles possess N2200-rich shells as the surface energy of P3HT $\left(26.9 \mathrm{~mJ} \mathrm{~m}^{-2}\right)$ is also higher than that of N2200. For the IDTBR-based nanoparticles, a P3HT-rich shell and o-IDTBR-rich core is attributed to the higher surface energy of o-IDTBR $\left(28.1 \mathrm{~mJ} \mathrm{~m}^{-2}\right)$ than P3HT, this structure then shifts to an eh-IDTBR-rich shell / P3HT-rich core for the P3HT:eh-IDTBR 
nanoparticles due to the lower surface energy of eh-IDTBR (18.3 $\mathrm{mJ} \mathrm{m}^{-2}$ ) relative to $\mathrm{P} 3 \mathrm{HT}$. A direct comparison can be made specifically to previous results reported for TQ1:fullerene ${ }^{34}$ and P3HT:fullerene ${ }^{29,35-37,73}$ systems, where the polymer donor occupies the nanoparticle shell for each case and the fullerene acceptor occupies the core.

We also note that the crystallinity of select donor polymer and NFA materials could potentially favour higher purity of the core (or shell) domains of the nanoparticles studied, but this property was not assessed further in our study.

\section{Conceptual Model for Core-Shell Flipping}

We observe a core-shell flipping driven by the low surface energy N2200 (23.7 $\mathrm{mJ} \mathrm{m}^{-2}$ ) and eh-IDTBR (18.3 $\mathrm{mJ} \mathrm{m}^{-2}$ ) NFA materials, where an inverted shell-core structure is the result of the NFA moving to the nanoparticle shell. A conceptual model illustrating this core-shell flipping driven by the relative surface energy of the donor and acceptor materials is presented in Figure 6. We also calculated the surface energy differential, $\Delta \mathrm{G}_{\text {surface, }}$, between components in the nanoparticle $(\Delta \mathrm{G}=$ $G_{\text {surface(acceptor) }}-G_{\text {surface(donor) }) \text {, plotting the relationship between }}$ nanoparticle shell composition and the surface energy differential in Figure 7, with tabulated data provided in Table 4. A linear correlation is observed between these two parameters, with the shell dominated by the material with the lower surface energy. In addition, we have plotted data points from our prior work reporting $\mathrm{P} 3 \mathrm{HT}: \mathrm{PC}_{61} \mathrm{BM}$ and TQ1: $\mathrm{PC}_{71} \mathrm{BM}$ nanoparticles, possessing a fullerene-rich core. This result indicates that the surface energy nanoengineering approach provides consistent results across multiple different materials systems. A distinct comparison can be observed between the morphology of donor:NFA nanoparticles and donor:fullerene acceptor nanoparticles. Due to the exceptionally high surface energy of the fullerene acceptors $\left(\mathrm{PC}_{61} \mathrm{BM}=38.2 \mathrm{~mJ} \mathrm{~cm}{ }^{-2} ; \mathrm{PC}_{71} \mathrm{BM}=39 \mathrm{~mJ}\right.$ $\mathrm{m}^{-2}$ ), synthetic flexibility is lost and the fullerene becomes strongly localized in the binary nanoparticle core regardless of the donor polymer. ${ }^{34,36}$ In contrast, our results show that inverted shell-core structured nanoparticles are now possible when using NFAs that are no longer pinned to such high surface energies, with the NFAs spanning a range of surface energies great enough to tune the nanoparticle shell composition between 20 and $71 \%$. The ability to span a range of $\Delta \mathrm{G}_{\text {surface }}$ values from positive to negative highlights that these NFA
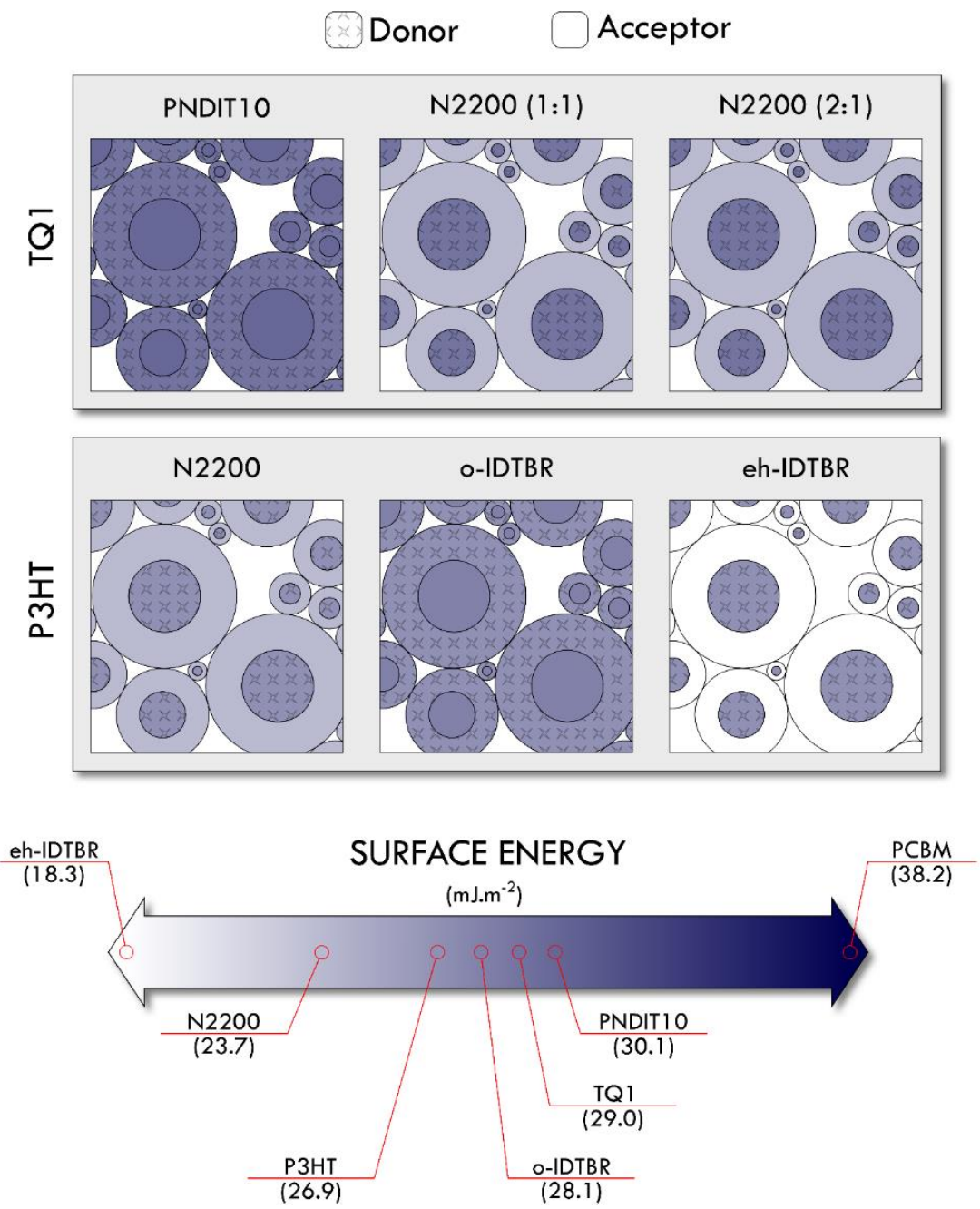

Figure 6 - Conceptual schematic incorporating core-shell structure observed for each donor-acceptor system, depicting the correlation between material surface energy and nanoparticle morphology. 
materials offer sophisticated control over internal nanoparticle morphology.

\section{Outlook for Engineered Nanostructures}

Here we establish a new figure of merit (FoM) for customizing the morphology of waterborne nanoparticulate colloidal inks, surface energy. With a $\Delta \mathrm{G}_{\text {surface }}>0$ yielding an acceptor core donor shell structure, a $\Delta \mathrm{G}_{\text {surface }}<0$ yielding a donor core acceptor shell structure (both determined empirically in this study), and a $\Delta G_{\text {surface }}=0$ leading to a molecularly intermixed structure (hypothesized from this work).

Interestingly, even small values of $\Delta G_{\text {surface }}$ of $\sim 1 \mathrm{~mJ} \mathrm{~m}^{-2}$ led to a phase separated core-shell structure for systems TQ1:PNDIT10 and P3HT:0-IDTBR. It is possible that for such small differences in the surface energy of the donor and acceptor materials, the morphology is also influenced by other factors, such as the nature of the surfactant. Indeed, Kosco et al. ${ }^{41}$ showed that when utilizing SDS surfactant, core-shell structures can be obtained for large chloroform/water surface tension differences between the donor containing chloroform phase and the acceptor.

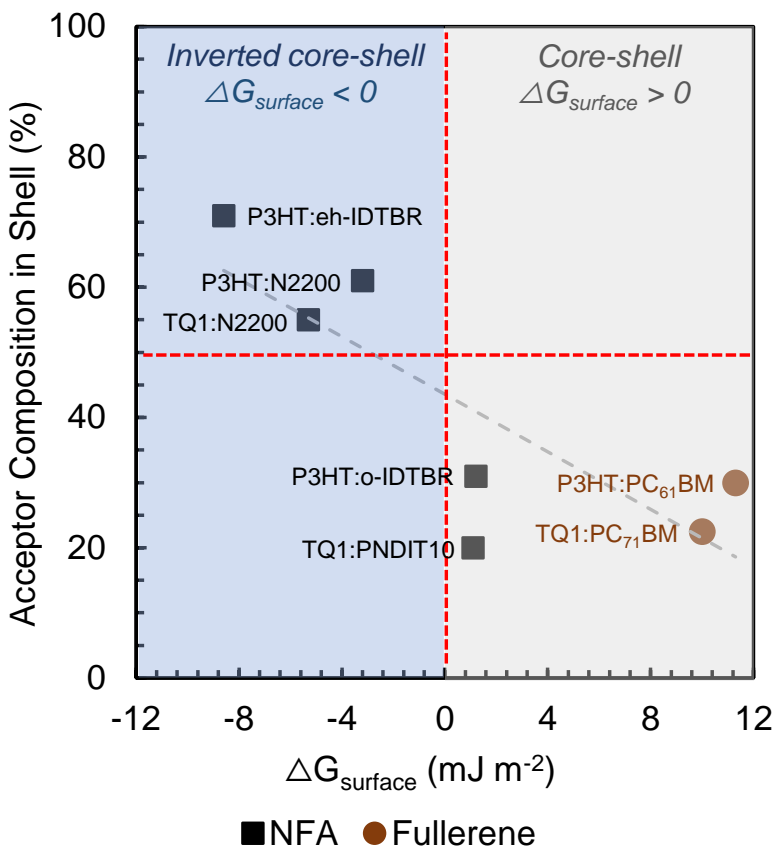

Figure 7 - Relationship between nanoparticle shell composition (\% acceptor Figure 7 - Relationship between nanoparticle shell
material) and surface energy differential $\left(\triangle \mathrm{G}_{\text {surface }}\right)$

Incorporation of NFAs into waterborne donor-acceptor nanoparticles has shown great promise in tuning the structure of nanoparticles due to the large surface energy variation possible with NFA materials in comparison to their fullerene counterparts. We have shown that matched surface energies of donor and acceptor materials is a viable strategy for targeting a molecularly intermixed nanoparticle structure, which is an important challenge for optimizing organic nanoparticles for highly efficient eco-friendly organic photovoltaics. This matching of surface energies could be achieved by synthetic modification of the NFA side chain chemistry in a systematic fashion in order to reach a desired target surface energy value for both acceptor and donor materials.

\section{Conclusions}

Here we report the acceptor core - donor shell and donor core - acceptor shell nanostructure formation of waterborne donoracceptor nanoparticles via self-assembly, driven by the surface energy of the NFA relative to the donor organic semiconductor material. During nanoparticle formation, to lower the energy of the free surface the higher surface energy material of the two materials is driven to the nanoparticle core, and the lower surface energy material to the nanoparticle shell. We observed a core-shell flipping driven by the low surface energy N2200 $\left(23.7 \mathrm{~mJ} \mathrm{~m}^{-2}\right)$ and eh-IDTBR (18.3 $\left.\mathrm{mJ} \mathrm{m}^{-2}\right)$ NFA materials, where an inverted shell-core structure was the result of the NFA moving to the nanoparticle shell. Customized waterborne nanoparticulate colloidal inks can be achieved by selecting donor and acceptor materials with a known surface energy differential. Furthermore, a highly promising strategy for generating intermixed donor-acceptor nanoparticles (as opposed to core-shell structured nanoparticles) is modification of the material surface energies via synthetic modification of a semiconductor's side chain chemistry to obtain matched surface energies for donor and acceptor, eliminating the drive for phase separation in the particle formation process. This morphology strategy has the goal of targeting nanostructured blends which promote efficient exciton dissociation and charge transport. The results of this study position surface energy to be a material property of equal importance to the existing key properties of organic semiconductors, namely, HOMO, LUMO, $E_{g}$ and $\lambda_{\max }$, for nano-engineering waterborne colloidal nanoparticles of organic semiconductors. We predict future studies of nanoparticle OPV will now involve five key criteria for the selection of suitable donor and acceptor materials, HOMO, LUMO, $E_{g}, \lambda_{\max }$ and surface energy.

\section{Conflicts of Interest}

There are no conflicts of interest to declare.

\section{Acknowledgements}

This research used resources of the Advanced Light Source, which is a DOE Office of Science User Facility under contract no. DE-AC02-05CH11231. The authors thank support staff at the Advanced Light Source synchrotron. We acknowledge travel funding provided by the International Synchrotron Access Program (ISAP) managed by the Australian Synchrotron, part of ANSTO, and funded by the Australian Government. Thank you to Dr Benjamin Watts and Dr Katharina Witte for NEXAFS measurements of eh-IDTBR at the Swiss Light Source, PolLux beamline. The PolLux endstation was financed by the BMBF through contracts 05K16WED and 05K19WE2. This work was performed in part at the Materials Node (Newcastle) of the Australian National Fabrication Facility (ANFF), which is a 
company established under the National Collaborative Research Infrastructure Strategy to provide nano- and microfabrication facilities for Australia's researchers. Thank you to the University of Newcastle Electron Microscopy and X-ray (EMX) Unit for providing access to electron microscopes. TWJ thanks the CSIRO Energy Business Unit for funding. Finally, we would like to thank Philippe Legros, CNRS Engineer at PLACAMAT UMS3626, CNRS-Univ. Bordeaux, 33600 PESSACFRANCE, for the preliminary SEM analysis and Robin Szymanski for providing UV-visible spectra of o- and eh-IDTBR.

\section{Abbreviations}

ALS, Advanced Light Source; $B H J$, bulk heterojunction; $E_{g}$, bandgap; FoM, figure of merit; $\Delta \mathrm{G}_{\text {surface, }}$ surface energy differential; HCP, hexagonally close packed; HOMO, highest occupied molecular orbital; IPES, inverse photoemission spectroscopy; LUMO, lowest unoccupied molecular orbital; NEXAFS, near edge $X$-ray absorption fine structure; NFA, nonfullerene acceptor; OPV, organic photovoltaics; PCE, power conversion efficiency; RCP, randomly close packed; SDS, sodium dodecyl sulfate; SLS, Swiss Light Source; STXM, scanning transmission X-ray microscopy; TEBS, sodium 2-(3thienyl)ethyloxybutylsulfonate; UPS, ultraviolet photoelectron spectroscopy.

\section{References}

1 Y. Zhong, L. Yin, P. He, W. Liu, Z. Wu and H. Wang, Surface Chemistry in Cobalt Phosphide-Stabilized Lithium - Sulfur Batteries. J. Am. Chem. Soc., 2018, 140, 1455-1459.

2 J. E. Newton, J. A. Preece, N. V. Rees and S. L. Horswell, Nanoparticle Catalysts for Proton Exchange Membrane Fuel Cells: Can Surfactant Effects Be Beneficial for Electrocatalysis? Phys. Chem. Che 2014, 16, 11435-11446.

3 S. Campisi, M. Schiavoni, C. E. Chan-thaw and A. Villa Untangling the Role of the Capping Agent in Nanocatalysis: Recent Advances and Perspectives. Catalysts 2016, 6 (12), 185.

4 M. Chang, and E. Reichmanis, An Approach to Core-Shell Nanostructured Materials with High Colloidal and Chemical Stability: Synthesis, Characterization and Mechanistic Evaluation. Colloid Polym. Sci. 2012, 290 (18), 1913-1926.

5 J. A. Bau, E. J. Luber and J. M. Buriak, Oxygen Evolution Catalyzed by Nickel-Iron Oxide Nanocrystals with a Nonequilibrium Phase. ACS Appl. Mater. Interfaces, 2015, 7 (35), 19755-19763.

6 M. Green, The Nature of Quantum Dot Capping Ligands. J. Mater. Chem. 2010, 20, 5797-5809.

7 C. Giansante and I. Infante, Surface Traps in Colloidal Quantum Dots: A Combined Experimental and Theoretical Perspective. J. Phys. Chem. Lett. 2017, 8, 5209-5215.

8 C. Goldmann, R. Lazzari, X. Paquez, C. Boissiere, F. Ribot, C. Sanchez, C. Chane and D. Portehault, Charge Transfer at Hybrid Interfaces: Plasmonics of Aromatic Thiol-Capped. ACS Nano 2015, 9 (7), 7572-7582.

9 N. Li, P. Zhao and D. Astruc, Anisotrope Gold-Nanopartikel: Synthese, Eigenschaften, Anwendungen Und Toxizitat. Angew. Chemie 2014, 126, 1784-1818.

10 R. Bardhan, S. Lal, A. Joshi and N. J. Halas, Theranostic Nanoshells: From Probe Design to Imaging and Treatment of Cancer. Acc. Chem. Res. 2011, 44 (10), 936-946.
11 A. N. Shipway, E. Katz and I. Willner, Nanoparticle Arrays on Surfaces for Electronic, Optical, and Sensor Applications. ChemPhysChem 2000, 1, 18-52.

12 J. A. Bau, P. Li, A. J. Marenco, S. Trudel, B. C. Olsen, E. J. Luber and J. M. Buriak, Nickel/Iron Oxide Nanocrystals with a Nonequilibrium Phase: Controlling Size, Shape, and Composition. Chem. Mater. 2014, 26 (16), 4796-4804.

13 D. L. Feldheim and C. D. Keating, Self-Assembly of Single Electron Transistors and Related Devices. Chem. Soc. Rev. 1998, 27, 1-12.

14 S. Gärtner, M. Christmann, S. Sankaran, H. Röhm, E.-M. Prinz, F. Penth, A. Pütz, A. E. Türeli, B. Penth, B. Baumstümmler and A. Colsmann, Eco-Friendly Fabrication of $4 \%$ Efficient Organic Solar Cells from Surfactant-Free P3HT:ICBA Nanoparticle Dispersions. Adv. Mater. 2014, 26, 6653-6657.

15 C. Xie, T. Heumüller, W. Gruber, X. Tang, A. Classen, I. Schuldes, M. Bidwell, A. Späth, R. H. Fink, T. Unruh, I. McCulloch, N. Li and C. J. Brabec, Overcoming Efficiency and Stability Limits in Water-Processing Nanoparticular Organic Photovoltaics by Minimizing Microstructure Defects. Nat. Commun. 2018, 9, 5335.

16 Y. Lee, J. Choi, K. J. Lee and N. E. Stott, Large-Scale Synthesis of Copper Nanoparticles by Chemically Controlled Reduction for Applications of Inkjet-Printed Electronics. Nanotechnology 2008, 19, 415604.

17 Z. Yang, J. Wei, Y. I. Sobolev and B. A. Grzybowski, Systems of Mechanized and Reactive Droplets Powered by MultiResponsive Surfactants. Nature 2018, 553, 313-318.

18 Z. Chu, J. Peng, and W. Jin, Advanced Nanomaterial Inks for Screen-Printed Chemical Sensors. Sensors Actuators B. Chem. 2017, 243, 919-926.

19 R. B. Grubbs, Roles of Polymer Ligands in Nanoparticle Stabilization Roles of Polymer Ligands in Nanoparticle Stabilization. Polym. Rev. 2007, 47, 197-215.

20 N. E. Persson, P. H. Chu, M. McBride, M. Grover and E. Reichmanis, Nucleation, Growth, and Alignment of Poly(3Hexylthiophene) Nanofibers for High-Performance OFETs. Acc. Chem. Res. 2017, 50 (4), 932-942.

21 S. Holliday, R. S. Ashraf, A. Wadsworth, D. Baran, S. A. Yousaf, C. B. Nielsen, C. H. Tan, S. D. Dimitrov, Z. Shang, N. Gasparini, M. Alamoudi, F. Laquai, C. J. Brabec, A. Salleo, J. R. Durant and I. McCulloch, High-Efficiency and Air-Stable P3HT-Based Polymer Solar Cells with a New Non-Fullerene Acceptor. Nat. Commun. 2016, 7, 11585.

22 Z. Li, X. Xu, W. Zhang, X. Meng, W. Ma, A. Yartsev, O. Inganäs, M. R. Andersson, R. A. J. Janssen and E. Wang, E. High Performance All-Polymer Solar Cells by Synergistic Effects of Fine-Tuned Crystallinity and Solvent Annealing. J. Am. Chem. Soc. 2016, 138, 10935-10944.

23 Q. Liu, Y. Jiang, K. Jin, J. Qin, J. Xu, W. Li, J. Xiong, J. Liu, Z. Xiao, K. Sun, S. Yang, X. Zhang and L. Ding, 18\% Efficiency Organic Solar Cells. Sci. Bull. 2020, 65 (4), 272-275.

24 H. Sun, T. Liu, J. Yu, T.-K. Lau, G. Zhang, Y. Zhang, M. Su, Y. Tang, R. Ma, B. Liu, J. Liang, K. Feng, X. Lu, X. Guo, F. Guo and H. Yan, A Monothiophene Unit Incorporating Both Fluoro and Ester Substitution Enabling High-Performance Donor Polymers for Non-Fullerene Solar Cells with $16.4 \%$ Efficiency. Energy Environ. Sci. 2019, 12, 3328-3337.

25 N. Espinosa, R. García-Valverde, A. Urbina and F. C. Krebs, A Life Cycle Analysis of Polymer Solar Cell Modules Prepared Using Roll-to-Roll Methods Under Ambient Conditions. Sol. Energy Mater. Sol. Cells 2011, 95 (5), 1293-1302.

26 K. Landfester, R. Montenegro, U. Scherf, R. Güntner, U. Asawapirom, S. Patil, D. Neher and T. Kietzke, Semiconducting Polymer Nanospheres in Aqueous Dispersion Prepared by a Miniemulsion Process. Adv. Mater. 2002, 14 (9), 651-655. 
27 T. Kietzke, D. Neher, K. Landfester, R. Montenegro, R. Güntner and U. Scherf, Novel Approaches to Polymer Blends Based on Polymer Nanoparticles. Nat. Mater. 2003, 2 (6), 408-412.

28 T. Kietzke, D. Neher, M. Kumke, R. Montenegro, K. Landfester and U. Scherf, A Nanoparticle Approach to Control the Phase Separation in Polyfluorene Photovoltaic Devices. Macromolecules 2004, 37 (13), 4882-4890.

29 S. Ulum, N.Holmes, M. Barr, A. L. D. Kilcoyne, B. Gong, B. Bin Bin; X. Zhou, W. Belcher, and P. Dastoor, The Role of Miscibility in Polymer:Fullerene Nanoparticulate Organic Photovoltaic Devices. Nano Energy 2013, 2, 897-905.

30 L. D'Olieslaeger, G. Pirotte, I. Cardinaletti, J. D'Haen, J. Manca, D. Vanderzande, W. Maes and A. Ethirajan, Eco-Friendly Fabrication of PBDTTPD:PC71BM Solar Cells Reaching a PCE of 3.8\% Using Water-Based Nanoparticle Dispersions. Org. Electron. physics, Mater. Appl. 2017, 42, 42-46.

31 J. Aubry, E. Ganachaud, J.-P. C. Addad and B. Cabane, Nanoprecipitation of Polymethylmethacrylate by Solvent Shifting: 1. Boundaries. Langmuir 2009, 25 (4), 1970-1979.

32 Y. Xia, C. Musumeci, J. Bergqvist, W. Ma, F. Gao, Z. Tang, S. Bai, Y. Jin, C. Zhu, R. Kroon, C. Wang, M. R. Andersson, L. Hou, O. Inganäs and E. Wang, Inverted All-Polymer Solar Cells Based on a Quinoxaline-Thiophene/Naphthalene-Diimide Polymer Blend Improved by Annealing. J. Mater. Chem. A 2016, 4 (10), 3835-3843.

33 M. T. Dang, L. Hirsch and G. Wantz, P3HT:PCBM, Best Seller in Polymer Photovoltaic Research. Adv. Mater. 2011, 23, 35973602.

34 N. P. Holmes, M. Marks, P. Kumar, R. Kroon, M. G. Barr, N. Nicolaidis, K. Feron, A. Pivrikas, A. Fahy, A. Diaz De Zerio Mendaza, A. L. D. Kilcoyne, C. Müller, X. Zhou, P. C. Dastoor and W. J. Belcher, Nano-Pathways: Bridging the Divide between Water-Processable Nanoparticulate and Bulk Heterojunction Organic Photovoltaics. Nano Energy 2016, 19, 495-510.

35 N. P. Holmes, K. B. Burke, P. Sista, M. Barr, H. D. Magurudeniya, M. C. Stefan, A. L. D. Kilcoyne, X. Zhou, P.C. Dastoor and W. J. Belcher, Nano-Domain Behaviour in P3HT:PCBM Nanoparticles, Relating Material Properties to Morphological Changes. Sol. Energy Mater. Sol. Cells 2013 117, 437-445.

36 S. Ulum, N. Holmes, D. Darwis, K. Burke, A. L. D. Kilcoyne, X Zhou, W. Belcher and P. Dastoor, Determining the Structura Motif of P3HT:PCBM Nanoparticulate Organic Photovoltaic Devices. Sol. Energy Mater. Sol. Cells 2013, 110, 43-48.

37 N. P. Holmes, N. Nicolaidis, K. Feron, M. Barr, K. B. Burke, M Al-Mudhaffer, P. Sista, A. L. D. Kilcoyne, M. C. Stefan, X. Zhou, X. P. C. Dastoor and W. J. Belcher, Probing the Origin of Photocurrent in Nanoparticulate Organic Photovoltaics. Sol. Energy Mater. Sol. Cells 2015, 140, 412-421.

38 F. Almyahi, T. R. Andersen, N. Cooling, N. P. Holmes, A. Fahy, M. G. Barr, A. L. D. Kilcoyne, W. Belcher and P. C. Dastoor Optimization, Characterization and Upscaling of Aqueous Solar Nanoparticle Inks for Organic Photovoltaics Using LowCost Donor:Acceptor Blend. Org. Electron. 2018, 52, 71-78.

39 M. F. Al-Mudhaffer, M. G. Griffith, K. Feron, N. Nicolaidis, N. A. Cooling, X. Zhou, J. Holdsworth, W. J. Belcher and P. C. Dastoor, The Origin of Performance Limitations in Miniemulsion Nanoparticulate Organic Photovoltaic Devices. Sol. Energy Mater. Sol. Cells 2018, 175 (September 2017), 7788 .

40 S. Subianto, R. Balu, L. De Campo, A. Sokolova, N. K. Dutta and N. R. Choudhury Sulfonated Thiophene Derivative Stabilized Aqueous Poly(3-Hexylthiophene):Phenyl-C61-Butyric Acid Methyl Ester Nanoparticle Dispersion for Organic Solar Cell Applications. ACS Appl. Mater. Interfaces 2018, 10, 4411644125.
41 J. Kosco, M. Bidwell, H. Cha, T. Martin, C. T. Howells, M. Sachs, D. H. Anjum, S. Gonzalez Lopez, L. Zou, A. Wadsworth, W. Zhang, L. Zhang, J. Tellam, R. Sougrat, F. Laquai, D. M. DeLongchamp, J. R. Durrant and I. McCulloch, Enhanced Photocatalytic Hydrogen Evolution from Organic Semiconductor Heterojunction Nanoparticles. Nat. Mater. 2020, 19 (5), 559-565.

$42 \mathrm{M}$. Rammal, P. Lévêque, G. Schlatter, N. Leclerc and A Hébraud, Recent Advances in the Green Processing of Organic Photovoltaic Devices from Nanoparticle Dispersions. Mater. Chem. Front. 2020, 4 (10), 2904-2931.

43 J. J. Richards, C. L. Whittle, G. Shao and L. D. Pozzo, Correlating Structure and Photocurrent for Composite Semiconducting Nanoparticles with Contrast Variation Small-Angle Neutron Scattering and Photoconductive Atomic Force Microscopy. ACS Nano 2014, 8, (5), 4313-4324.

44 Z. Ma, B. Zhao, Y. Gong, J. Deng, Z. Tan, Z. Green-SolventProcessable Strategies for Achieving Large-Scale Manufacture of Organic Photovoltaics. J. Mater. Chem. A 2019, 7, 2282622847

45 N. P. Holmes, M. Marks, J. M. Cave, K. Feron, M. G. Barr, A Fahy, A. Sharma, X. Pan, A. L. D. Kilcoyne, X. Zhou, D. A. Lewis, M. R. Andersson, J. van Stam, A. B. Walker, E. Moons, W. J. Belcher and P. C. Dastoor, Engineering Two-Phase and ThreePhase Microstructures from Water-Based Dispersions of Nanoparticles for Eco-Friendly Polymer Solar Cell Applications. Chem. Mater. 2018, 30, 6521-6531.

46 E. Wang, L. Hou, Z. Wang, S. Hellström, F. Zhang, O. Inganäs and M. R. Andersson, An Easily Synthesized Blue Polymer for High-Performance Polymer Solar Cells. Adv. Mater. 2010, 22 (46), 5240-5244.

47 A. L. D. Kilcoyne, T. Tyliszczak, W. F. Steele, S. Fakra, P. Hitchcock, K. Franck, E. Anderson, B. Harteneck, E. G. Rightor, G. E. Mitchell, A. P. Hitchcock, L. Yang, T. Warwick and H. Ade, Interferometer-Controlled Scanning Transmission X-Ray Microscopes at the Advanced Light Source. J. Synchrotron Radiat. 2003, 10, 125-136.

48 R. Hansson, L. K. E. Ericsson, N. P. Holmes, J. Rysz, A. Opitz, M. Campoy-Quiles, E. Wang, M. G. Barr, A. L. D. Kilcoyne, X. Zhou, P. Dastoor and E. Moons, Vertical and Lateral Morphology Effects on Solar Cell Performance for a ThiopheneQuinoxaline Copolymer:PC70BM Blend. J. Mater. Chem. A 2015, 3, 6970-6979.

49 X. Wang, T. Ederth and O. Inganäs, In Situ Wilhelmy Balance Surface Energy Determination of Poly(3-Hexylthiophene) and Poly(3,4-Ethylenedioxythiophene) during Electrochemical Doping-Dedoping. Langmuir 2006, 22, 9287-9294.

50 S. Wang, S. Fabiano, S. Himmelberger, S. Puzinas, X. Crispin, A Salleo and M. Berggren, Experimental Evidence That ShortRange Intermolecular Aggregation Is Sufficient for Efficient Charge Transport in Conjugated Polymers. Proc. Natl. Acad. Sci. U. S. A. 2015, 112 (34), 10599-10604.

51 S. Fabiano, S. Himmelberger, M. Drees, Z. Chen, R. M. Altamimi, A. Salleo, M. A. Loi and A. Facchetti, Charge Transport Orthogonality in All-Polymer Blend Transistors, Diodes, and Solar Cells. Adv. Energy Mater. 2014, 4, 1301409.

52 Q. Liang, X. Jiao, Y. Yan, Z. Xie, G. Lu, J. Liu and Y. Han, Separating Crystallization Process of P3HT and O-IDTBR to Construct Highly Crystalline Interpenetrating Network with Optimized Vertical Phase Separation. Adv. Funct. Mater. 2019, 29 (47), 1807591.

53 L. Krishnan Jagadamma, R. G. D. Taylor, A. L. Kanibolotsky, M. T. Sajjad, I. A. Wright, P. N. Horton, S. J. Coles, I. D. W. Samuel and P. J. Skabara, Highly Efficient Fullerene and Non-Fullerene Based Ternary Organic Solar Cells Incorporating a New Tetrathiocin-Cored Semiconductor. Sustain. Energy Fuels 2019, 3 (8), 2087-2099. 
54 F. M. Fowkes, Attractive Forces at Interfaces. Ind. Eng. Chem. 1964, 56 (12), 40-52.

55 H. W. Chen, T. Y. Huang, T. H. Chang, Y. Sanehira, C. W. Kung C. W. Chu, M. Ikegami, T. Miyasaka and K. C. Ho, Efficiency Enhancement of Hybrid Perovskite Solar Cells with MEH-PPV Hole-Transporting Layers. Sci. Rep. 2016, 6 (September), 1-9.

56 A. Wadsworth, Z. Hamid, M. Bidwell, R. S. Ashraf, J. I. Khan, D. H. Anjum, C. Cendra, J. Yan, E. Rezasoltani, A. A. Guilbert, M Azzouzi, N. Gasparini, J. H. Bannock, D. Baran, H. Wu, J. C. de Mello, C. J. Brabec, A. Salleo, J. Nelson, F. Laquai and I. McCulloch, Progress in Poly (3-Hexylthiophene) Organic Solar Cells and the Influence of Its Molecular Weight on Device Performance. Adv. Energy Mater. 2018, 8, 1801001.

57 Z. L. Guan, J. B. Kim, H. Wang, C. Jaye, D. A. Fischer, Y. L. Loo A. Kahn, Direct Determination of the Electronic Structure of the Poly(3-Hexylthiophene):Phenyl-[6,6]-C61 Butyric Acid Methyl Ester Blend. Org. Electron. 2010, 11 (11), 1779-1785.

58 N. C. Nicolaidis, M. F. Al-Mudhaffer, J. Holdsworth, X. Zhou, W. J. Belcher and P. C. Dastoor, The Contribution of Fullerene Photocurrent Generation to Organic Solar Cell Performance. J. Phys. Chem. C 2019, 123, 11950-11958.

59 C. M. Björström, A. Bernasik, J. Rysz, A. Budkowski, S. Nilsson, M. Svensson, M. R. Andersson, K. O. Magnusson and E. Moons, Multilayer Formation in Spin-Coated Thin Films of Low-Bandgap Polyfluorene:PCBM Blends. J. Phys. Condens. Matter 2005, 17 (50), L529-L534.

60 E. L. Ratcliff, J. Meyer, K. X. Steirer, N. R. Armstrong, D. Olson and A. Kahn, Energy Level Alignment in PCDTBT:PC70BM Solar Cells: Solution Processed NiOx for Improved Hole Collection and Efficiency. Org. Electron. 2012, 13 (5), 744-749.

61 T. A. Chen, X. Wu and R. D. Rieke, Regiocontrolled Synthesis of Poly(3-Alkylthiophenes) Mediated by Rieke Zinc: Their Characterization and Solid-State Properties. J. Am. Chem. Soc. 1995, 117, 233-244.

62 J. Clark, C. Silva, R. H. Friend and F. C. Spano, Role of Intermolecular Coupling in the Photophysics of Disordered Organic Semiconductors: Aggregate Emission in Regioregular Polythiophene. Phys. Rev. Lett. 2007, 98, 206406.

63 A. Sharma, X. Pan, J. A. Campbell, M. R. Andersson and D. A. Lewis, Unravelling the Thermomechanical Properties of Bulk Heterojunction Blends in Polymer Solar Cells. Macromolecules 2017, 50, 3347-3354.
64 K. W. Desmond and E. R. Weeks, Random Close Packing of Disks and Spheres in Confined Geometries. Phys. Rev. E Phys. Rev. E, 2009, 80, 051305.

65 K. W. Desmond and E. R. Weeks, Influence of Particle Size Distribution on Random Close Packing of Spheres. Phys. Rev. E - Stat. Nonlinear, Soft Matter Phys. 2014, 90 (2), 1-6.

66 S. I. Stoeva, B. L. V. Prasad, S. Uma, P. K. Stoimenov, V. Zaikovski, C. M. Sorensen and K. J. Klabunde, Face-Centered Cubic and Hexagonal Closed-Packed Nanocrystal Superlattices of Gold Nanoparticles Prepared by Different Methods. J. Phys. Chem. B 2003, 107 (30), 7441-7448.

67 C. R. McNeill, B. Watts, L. Thomsen, W. J. Belcher, N. C. Greenham and P. C. Dastoor, Nanoscale Quantitative Chemical Mapping of Conjugated Polymer Blends. Nano Lett. 2006, 6, 1202-1206.

68 S. Gärtner, A. J. Clulow, I. A. Howard, E. P. Gilbert, P. L. Burn, I. R. Gentle and A. Colsmann, Relating Structure to Efficiency in Surfactant-free Polymer:Fullerene Nanoparticle-based Organic Solar Cells. ACS Appl. Mater. Interfaces, 2017, 9, 42986-42995.

69 S. N. Clafton, D. M. Huang, W. R. Massey and T. W. Kee, Femtosecond Dynamics of Excitons and Hole-Polarons in Composite P3HT/PCBM Nanoparticles. J. Phys. Chem. B, 2013, $117(16), 4626-4633$.

70 K. N. Schwarz, S. B. Farley, T. A. Smith and K. P. Ghiggino, Charge Generation and Morphology in P3HT:PCBM Nanoparticles Prepared by Mini-emulsion and Reprecipitation Methods. Nanoscale, 2015, 7, 19899-19904.

71 J. H. Huang, Y. S. Hsiao, E. Richard, C. C. Chen, P. Chen, G. Li, C. W. Chu and Y. Yang, The Investigation of Donor-Acceptor Compatibility in Bulk-Heterojunction Polymer Systems. Appl. Phys. Lett. 2013, 103 (4), 043304.

72 N. P. Holmes, H. Munday, M. G. Barr, L. Thomsen, M. A Marcus, A. L. D. Kilcoyne, A. Fahy, J. van Stam, P. C. Dastoor and E. Moons, Unravelling Donor-Acceptor Film Morphology Formation for Environmentally-Friendly OPV Ink Formulations. Green Chem. 2019, 21, 5090-5103.

73 F. Almyahi, T. R. Andersen, N. Cooling, N. P. Holmes, A. Fahy, M. G. Barr, D. Kilcoyne, W. Belcher, and P. C. Dastoor, Optimization, Characterization and Upscaling of Aqueous Solar Nanoparticle Inks for Organic Photovoltaics Using LowCost Donor : Acceptor Blend. Org. Electron. 2018, 52, 71-78. 